ISSN: 0213-2079 - ISSN electrónico: 2386-3889

DOI: https://doi.org/10.14201/shhmo2019411189230

\title{
MODELOS DE SOBERANÍA Y DIPLOMACIA. LAS REPÚBLICAS MERCANTILES DE GÉNOVA Y LAS PROVINCIAS UNIDAS ANTE EL CONFLICTO HISPANO- FRANCÉS POR LA HEGEMONÍA (1635-1659) ${ }^{1}$
}

\section{Models of Sovereingty and Diplomacy. The Mercantile Republics of Genoa and the United Provinces before the Spanish-French Struggle for Sovereignty (1635-1659)}

\section{Manuel HERRERO SÁNCHEZ \\ Universidad Pablo de Olavide de Sevilla \\ Correo-e: mahersan@upo.es}

RESUMEN: El presente artículo analiza el papel jugado por las repúblicas mercantiles de Génova y las Provincias Unidas en el conflicto hispanofrancés por la hegemonía en el que entraban en disputa dos modelos de soberanía contrapuestos. Entre 1635, momento del estallido del conflicto entre Madrid y París, y la firma de la paz de los Pirineos en 1659, ambas repúblicas experimentarán un cambio en la tradicional relación mantenida hasta el momento con la Monarquía Hispánica: en la república ligur se cuestionarán los sólidos lazos que la unían al monarca Católico desde 1528 y se impondrán aquellos sectores que apostaban por la neutralidad y la plena autonomía; en las Provincias Unidas, una vez firmada la paz de Münster en 1648, que ponía fin a un agotador conflicto de 80 años, se impondrán aquellos grupos de poder favorables a una alianza con la Monarquía

1. El presente trabajo se enmarca dentro del proyecto de investigación radicado en la Universidad Pablo de Olavide y financiado por el Ministerio de Ciencia, Innovación y Universidades con fondos FEDER de la Unión Europea del que soy responsable en la actualidad bajo el título Res Publica monárquica. La Monarquía Hispánica, una estructura imperial policéntrica de repúblicas urbanas (PGC2018-095224-B-I00). 
Hispánica junto a la que la república pondrá en pie el sistema de alianzas internacionales destinado a frenar la política expansionista de Luis XIV y a velar por la estabilidad internacional. A partir de la invasión de ambas repúblicas por parte de Francia en 1672, que culminará en el bombardeo de Génova en 1684, tanto las Provincias Unidas como la república ligur acabarán consolidando sus buenas relaciones con el monarca Católico que se erigió, junto al Emperador, en uno de los principales garantes de la supervivencia de este tipo de estructuras políticas policéntricas de marcado carácter urbano cuya autonomía se veía cuestionada por el nuevo modelo de soberanía plena postulado por Francia.

Palabras clave: Monarquía Hispánica; Francia; repúblicas; republicanismo; Génova; Provincias Unidas; hegemonía; diplomacia; policentrismo; soberanía; modelos estatales.

ABSTRACT: The present article analyses the role played by the mercantile republics of Genoa and the United Provinces in the Spanish-French struggle for hegemony, which confronted two contradictory models of sovereignty. Between the beginning of the conflict in 1635 and the signing of the Peace of the Pyrenees in 1659, both republics changed their traditional policy towards the Spanish Monarchy. The Ligurian republic questioned the strong bonds that, since 1528 had tied the republic's destiny to that of the Hispanic Monarchy, with the autonomy-party gaining increasing political prominence; the Netherlands, for their part, became the main ally of the Spanish Monarchy after the Peace of Munster, in 1648, which finally brought an end to the exhausting 80 -year war between them. This alliance was the cornerstone of the system of coalitions created in order to put a stop to Louis XIV's expansionism and restore international balance. The French invasion of both republics in 1672, leading up to the bombardment of Genoa in 1684, consolidated the relationship between them and the Catholic monarch who, alongside the Emperor, became one of the main guarantors of the survival of this sort of, eminently urban, polycentric political structures, whose autonomy was being challenged by the new sovereignty model being pushed forth by France.

Keywords: Hispanic monarchy; France; republics; republicanism; Genoa; United Provinces; hegemony; diplomacy; polycentrism; state models. 
MANUEL HERRERO SÁNCHEZ

LAS REPÚBLICAS MERCANTILES DE GÉNOVA Y LAS PROVINCIAS UNIDAS

ANTE EL CONFLICTO HISPANO-FRANCÉS POR LA HEGEMONÍA (1635-1659)

\section{EL CONFLICTO HISPANO-FRANCÉS: DOS MODELOS DE SOBERANÍA EN LITIGIO EN UN PANORAMA INTERNACIONAL CAMBIANTE}

El conflicto militar entablado entre Francia y la Monarquía Hispánica entre 1635 y la firma de la paz de los Pirineos en 1659 no fue tan sólo la culminación del tradicional enfrentamiento dinástico entre los Habsburgo y los Valois-Borbón o una mera pugna entre las dos principales potencias territoriales del momento por la hegemonía internacional. Se trataba, ante todo, de un choque entre dos modelos de soberanía que ponía de manifiesto la pluralidad de las formas de organización estatal durante la Edad Moderna y que, como ha subrayado Joaquim Albareda, alcanzaría su máxima expresión a la muerte de Carlos II con el estallido de la Guerra de Sucesión ${ }^{2}$. A pesar de la existencia de evidentes concomitancias ${ }^{3}$ y de que convenga mantener cierta prevención ante cualquier forma de modelización simplificadora que, como han advertido Anne Dubet y José Javier Ruiz Ibáñez, entraña el riesgo de ofrecer imágenes demasiado rígidas y cercanas a la obsesión identitaria propia de la historiografía nacionalista ${ }^{4}$, resulta indiscutible que, como se observa en todo tipo de memoriales, panfletos, arbitrios, consultas y, de forma especial, en la nutrida correspondencia diplomática o mercantil, los propios contemporáneos parecieron ser conscientes de la existencia de patrones diferentes y de la diversidad de las soluciones adoptadas por ambas monarquías. En efecto, el necesario proceso de rehistorización y contextualización conceptual a la hora de acercarnos a las estructuras políticas del Antiguo Régimen nos obliga a abordar dichas realidades desde su propia racionalidad y a cuestionar cualquier género de narrativa teleológica que conduciría, de forma inevitable, al triunfo de los modelos centralizados, homogéneos y de soberanía plena propios del estado nación contemporáneo ${ }^{5}$.

2. Momento en el que, según señala, se confrontaron: «dos concepciones distintas sobre la política, fruto de desarrollos seculares que permitieron cristalizar modelos institucionales, normas políticas y actitudes harto diferentes.» En ALBAREDA SALVADÓ, J.: La Guerra de Sucesión española (1700-1714). Barcelona, 2010, p. 6.

3. SCHAUB, J.-F.: La France espagnole. Les racines hispaniques de l'absolutisme français. París, 2003.

4. DUBET, A. y RUIZ IBÁÑEZ, J. J. (ed.): Las monarquías española y francesa (siglos XVI-XVIII). ¿Dos modelos políticos? Madrid, 2010.

5. Planteamientos presentistas que, a pesar de las agudas consideraciones realizadas en su día por Antonio Manuel Hespanha, Bartolomé Clavero, Pietro Costa, Pablo Fernández Albaladejo o Giorgio Chittolini, se resisten a desaparecer. Al respecto véase el interesante balance realizado hace ya algunos años por SCHAUB, J-F.: «La Peninsola Iberica nei secoli XVI e XVII: la questione dello stato», Studi Storici 36, 1995, pp. 9-50 o el excelente volumen de CHITTOLINI, G., MOLHO, A. y SCHIERA, P. (eds.): Origini dello Stato. Processi di formazione statale in Italia fra medioevo ed età moderna. Bolonia, 1994. Un reciente balance sobre el concepto de Estado Moderno en BENIGNO, F.: Las palabras del tiempo. Un ideario para pensar históricamente. Madrid, 2013, pp. 199-222.

Ediciones Universidad de Salamanca / @®@@ Stud. his., H. ${ }^{a}$ mod., 41, n. 1 (2019), pp. 189-230 
Durante los 24 años de duración del conflicto, Europa sufrió una serie de estallidos revolucionarios generalizados que, motivados, en gran medida, por las exigencias fiscales derivadas de un estado de guerra permanente, entrañaron importantes transformaciones sociales e institucionales 6 . La Monarquía Hispánica y Francia respondieron a través de dos vías diametralmente opuestas a este tipo de «turbolenze» $\mathrm{O}$ «pericolosi accidenti», como las definió en una sugerente visión de conjunto aparecida en Venecia en 1654 el genovés, Giambattista Birago ${ }^{7}$. Según ha señalado Luis Ribot, Madrid se inclinó por la clemencia regia y por la recuperación de la política de consenso ${ }^{8}$. Se trataba de restablecer el modelo de gobernanza policéntrico que había sido puesto en cuestión durante el valimiento del conde duque de Olivares'. La memoria de las desastrosas consecuencias de la rebelión de Flandes actuó como un antídoto a la hora de restituir el orden tras la oleada de revueltas que durante la década de 1640 asolaron Cataluña, Sicilia y Nápoles y que, como evidenció la independencia de Portugal, estuvieron a punto de provocar la desmembración de la monarquía ${ }^{10}$. La legitimidad del soberano reposaba en un riguroso acatamiento de las formas de gobierno mixto y de las libertades y franquicias de cada uno de los territorios bajo su jurisdicción. La doctrina política dominante se sustentaba en el hecho de que, en última instancia, la soberanía radicaba en el pueblo que la transfería, por voluntad divina, a su legítimo soberano por lo que el cuestionamiento de los privilegios e inmunidades de las distintas corporaciones que conformaban el cuerpo político podía considerarse como un acto de tiranía que quebrantaba el deber de obediencia. Las fuertes limitaciones doctrinales, éticas e institucionales al poder del soberano explican que la Monarquía Hispánica se caracterizase por una

6. En 1650, el embajador español en La Haya señalaba a su homólogo en Venecia, marqués de la Fuente, en respuesta a una carta en la que le comentaba las protestas que se extendían en Terra Ferma: «veo que allí hay revueltas como en todas partes.» Carta de Antoine Brun al marqués de la Fuente, La Haya a 15 de septiembre de 1650, en Archivo General de Simancas (AGS), Embajada de España en la Haya (EEH), Estado, leg. 3643.

7. BIRAGO AVOGADRO, G.: Turbolenze di Europa dall'anno 1640 fino al 1650. Venecia, 1654.

8. RIBOT GARCÍA, L.A.: «Ira regis o clementia. El caso de Mesina y la respuesta a la rebelión en la Monarquía de España», en GARCÍA, B. y ÁLVAREZ-OSSORIO, A. (eds.): Visperas de sucesión. Europa y la Monarquía de Carlos II. Madrid, 2015, pp. 129-157.

9. En un reciente trabajo, Manuel Rivero, para el que resulta más que cuestionable considerar a la Monarquía Hispánica como una mera confederación de estados agregados al tratarse de un patrimonio dinástico cuya cohesión se sustentaba en la casa real, la política reformista de Olivares no respondía a un deseo de centralización como acreditaría el cuestionamiento del sistema polisinodial o el reforzamiento de la autonomía de los virreyes, RIVERO RODRÍGUEZ, M.: El conde duque de Olivares. La búsqueda de la privanza perfecta., Madrid, 2017.

10. HERRERO SÁNCHEZ, M.: «La memoria de la revuelta de Flandes en la toma de decisiones y en la acción política de la Monarquía Hispánica entre 1621 y 1700», en MERLE, A., JETTOT, S. y HERRERO SANCHEZ, M. (eds.): La Mémoire des révoltes en Europe à l'époque moderne. París, 2018, pp. 309-331.

Ediciones Universidad de Salamanca / అ@@ Stud. his., H. ${ }^{a}$ mod., 41, n. 1 (2019), pp. 189-230 
marcada compartimentación de la soberanía entre una miríada de poderes y corporaciones, de mayor o menor jerarquía, en la que determinados deberes morales o de amistad, como la gracia y las redes clientelares, ejercían un notable protagonismo. Aunque el soberano, en calidad de última instancia jurisdiccional, apareciese como el responsable de restablecer la equidad entre los diversos cuerpos que conformaban la república, el derecho legislativo de la corona se veía limitado por el ius comune y por los usos y las prácticas jurídicas locales ${ }^{11}$.

Lejos de aspirar al pleno monopolio de la soberanía en línea con los postulados puestos en marcha por Jean Bodin en Francia a partir de finales del siglo XVI, el rey Católico actuaba como la cabeza de una estructura política plural y policéntrica, caracterizada por la dispersión de atribuciones administrativas y judiciales en la que cada uno de los cuerpos que constituían el conjunto mantenía atribuciones privativas y participaba de forma activa en el gobierno, que estaba lejos de articularse tan sólo a través de una relación radial entre el centro y las distintas periferias ${ }^{12}$. El imponente peso de lo local nos permite cuestionar la pretendida inadecuación entre la defensa de las libertades urbanas y el agregado imperial de los Habsburgo ${ }^{13}$. A pesar de que se produjeran estallidos revolucionarios puntuales en aquellos momentos en los que se ponía en cuestión el ordenamiento constitucional sobre el que se articulaba el consenso, la Monarquía Hispánica se caracterizó por la existencia de una variopinta diversidad de redes urbanas que trabaron diferentes formas de colaboración con el rey y que, al igual que ocurrió en el resto de Europa, experimentaron un notable proceso de ennoblecimiento y de cierre oligárquico que favoreció la vinculación de intereses entre sus respectivas élites y la política imperial de la corona. Dichas ciudades, que gozaban de un fuerte margen de autonomía, contaban con dinámicos espacios de representación política desde los que ejercían un rígido control sobre la política fiscal ${ }^{14}$ por lo que, a la postre, vieron mejor garantizadas sus libertades y

11. CARDIM, P.: «La jurisdicción real y su afirmación en la Corona portuguesa y sus territorios ultramarinos (siglos XVI-XVIII). Reflexiones sobre la historiografía», en ARANDA PÉREZ, F. J. y DAMIÀO RODRIGUES, J. (eds.): De Re Publica Hispaniae. Una vindicación de la cultura politica en los reinos ibéricos en la primera modernidad. Madrid, 2008, pp. 349-388.

12. CARDIM, P., HERZOG, T., RUIZ IBÁÑEZ J. J. y SABATINI, G. (eds.): Polycentric Monarchies. How Did Early Modern Spain and Portugal Achieve and Maintain A Global Hegemony? Eastbourne, 2012.

13. Al respecto, véanse los planteamientos de Charles Tilly y Wim Blockmans según los cuales la consolidación del Estado Moderno se sustentaba en la concentración del poder en manos del soberano a expensa de las autoridades locales y mediante la domesticación de la nobleza y el recorte sistemático de la autonomía y las libertades municipales. TILLY, C. y BLOCKMANS, W. P. (eds.): Cities and the Rise of States in Europe, A.D. 1000 to 1800. San Francisco y Oxford, 1994.

14. HERRERO SÁNCHEZ, M.: «Urban Republicanism and Political Representation in the Spanish Monarchy», en ALBAREDA, J. y HERRERO SÁNCHEZ, M. (eds.): Political Representation in the Ancien Régime,). Londres/New York, 2018, pp. 319-332.

Ediciones Universidad de Salamanca / @®@@ Stud. his., H. ${ }^{a}$ mod., 41, n. 1 (2019), pp. 189-230 
privilegios en el interior de la Monarquía Hispánica que en el seno de otros sistemas dinásticos que, como el francés, lograron limitar con mayor eficacia dicha autonomía. Situación que explica la relativa estabilidad social de una estructura imperial dispersa que no sólo logró mantener en su interior la homogeneidad religiosa, sino que pudo también hacer frente al permanente estado de guerra sin erosionar en exceso los fueros, leyes y costumbres de cada uno de los dominios del rey.

El reino de Francia, aunque compartía con la Monarquía Católica un buen número de elementos en común que habían favorecido el establecimiento de lazos dinásticos entre ambas coronas como una de las vías más adecuadas para resolver el permanente estado de guerra, experimentó una serie de transformaciones institucionales derivadas de los sangrientos conflictos civiles y religiosos que habían devastado el reino durante la segunda mitad del siglo XVI. El hecho de que el rey Cristianísimo ejerciese su jurisdicción sobre un espacio territorial compacto y el creciente protagonismo de París en la toma de decisiones facilitaron la aplicación de una forma de gobierno más ejecutivo caracterizado por un fortalecimiento del poder soberano del rey ${ }^{15}$. El estallido de la Fronda entre 1648 y 1652 durante la minoría de edad de Luis XIV canalizó el resentimiento experimentado por un buen número de corporaciones y estamentos ante la erosión a sus privilegios derivada de la política puesta en marcha por Richelieu y por Mazarino para hacer frente al agotador esfuerzo bélico. En las memorias redactadas por uno de los principales protagonistas de los tumultos, el duque de la Rochefoucault, en torno a la guerra civil que volvió a sacudir el reino durante dichos años se recogen, de forma elocuente, las principales acusaciones contra la política de ambos cardenales:

con el pretexto de pública necesidad por ocasión de las guerras de afuera y defensa del Estado habiendo comenzado por el Cardenal de Richelieu se continuaban después de su muerte parece preciso tocar algo de ello. Aquel ministro, siendo absoluto dueño del poder de su príncipe para alargar sin medida la autoridad del soberano había destruido y violado con su nueva política las más antiguas leyes y constituciones del Estado. Tuvo siempre por máxima asentada y cierta que todos los reglamentos y estatutos antiguos del reino eran más concesiones forzosas a que los vasallos para templar la autoridad soberana habían obligado a sus príncipes, que leyes necesarias y fundamentos sólidos del buen gobierno y habiendo el suyo, que duró tanto, tenido siempre de parte a la fortuna más conocida por la felicidad de sucesos que por la madurez de los consejos, cobró su disposición tanto crédito

15. No obstante, resulta conveniente cuestionar la visión estereotipada del absolutismo francés. Al respecto véase JOUANNA, A.: Le pouvoir absolu, Naissance de l'imaginaire politique de la royauté. París, 2013. Por su parte James Collins subraya la persistencia de un vocabulario de fuerte sesgo republicano en las ciudades francesas incluso durante el gobierno personal de Luis XIV: COLLINS, J. B.: La monarchie républicaine. État et société dans la France moderne. París, 2016. 
que sin oposición alguna trabucó toda la forma antigua en la administración de la justicia y de la hacienda estableciendo por supremo tribunal de todo la sola voluntad del rey de que él disponía [Continúa su narración con un balance de la política aplicada por Mazarino tras su control del gobierno de la regencia] Para conseguir más (después de haber apurado con imposiciones y tributo nuevos la sustancia de los labradores y gente del campo) revolvió hacia las villas y ciudades, imponiendo sobre las haciendas de los ricos y los pobres erigiendo y vendiendo oficios nuevos, quitando los gajes a los ministros, apoderándose del rédito de los juros, pidiendo préstamos, e inventando pragmáticas nuevas y nunca oídas para sacar dinero como quiera que fuese. Con este género de proceder tan sin medida fue disponiendo los ánimos de los Parlamentos, de las comunidades, de las villas y ciudades a una revuelta universal de todo el reino [...] Sintió el Parlamento (como era justo) la queja universal del reino, admitió sus memoriales, prometiendo de administrar justicia con que interesándose en la calamidad del pueblo le granjeó las voluntades con tanto aplauso de todos que públicamente los miembros de aquel cuerpo eran aclamados como dioses vengadores de la libertad francesa ${ }^{16}$.

Tras el sometimiento por la fuerza de las armas del último reducto rebelde en Burdeos en julio de 1653, la consolidación del poder soberano del monarca se consolidó sin necesidad de realizar ningún tipo de concesiones para alcanzar su máxima expresión tras el control personal del poder por parte de Luis XIV a la muerte de Mazarino en 1661.

No obstante, como consecuencia de la Fronda y de los positivos efectos del acuerdo de paz alcanzado entre la Monarquía Hispánica y las Provincias Unidas en enero de 1648, que permitió cerrar el frente norte en Flandes y disponer de los efectivos navales y de los servicios financieros y mercantiles de dicha república, el monarca católico logró sofocar los tumultos de Nápoles y Sicilia y recuperar en 1652 tanto Cataluña como un buen número de plazas como Casale, en el norte de Italia, o Dunkerque. Este constante cambio de escenario nos obliga a manejar con prudencia conceptos como preponderancia o hegemonía pero también decadencia o declive ${ }^{17}$. Según indicó en su momento Jonatán Israel en un excelente balance sobre la posición internacional de la Monarquía Hispánica entre las paces de Westfalia y de los Pirineos, durante gran parte de la década de 1650 a los ojos de los contemporáneos la supremacía de Francia estaba lejos de resultar indiscutible ${ }^{18}$. Así se lo

16. Memorias del duque de la Rochefoucault de las guerras civiles de Francia del año 1648, Biblioteca Nacional de Madrid (BNM), Mss, 2379, fol. 3-16. Aunque La Rochefoucault volvió a la corte tras el fallecimiento de Mazarino, la publicación de forma clandestina de una versión de sus memorias en Bruselas en 1662 provocó un fuerte impacto.

17. Véanse al respecto las agudas consideraciones de BRAUN, G.: Du roi Soleil aux Lumières. Histoire Franco-allemande. Lille, 2012, p. 6.

18. ISRAEL, J. I: «Spain and Europe from the Peace of Münster to the Peace of the Pyrénnées, 1648-1659», en ISRAEL, J. I.: Conflicts of Empires. Spain, the Low Countries and

Ediciones Universidad de Salamanca / 요 Stud. his., H. ${ }^{a}$ mod., 41, n. 1 (2019), pp. 189-230 
MANUEL HERRERO SÁNCHEZ

LAS REPÚBLICAS MERCANTILES DE GÉNOVA Y LAS PROVINCIAS UNIDAS

ANTE EL CONFLICTO HISPANO-FRANCÉS POR LA HEGEMONÍA (1635-1659)

hacía saber el conde de Peñaranda a Don Luis de Haro en una carta enviada en mayo de 1648 en la que se felicitaba por el control de la situación en Nápoles y por la definitiva ratificación del acuerdo de paz alcanzado con las Provincias Unidas lo que, sumado a un posible logro militar en Flandes y a la conmoción que se esperaba que estallase en Francia, podría abrir un «camino anchísimo para llegar a una paz razonable» ${ }^{19}$. En efecto, como ha señalado Daniel Séré, la recuperación militar española estuvo estrechamente vinculada a las maniobras tejidas por la Monarquía Hispánica desde Bruselas donde recalaban algunos de los principales grupos de descontentos contra la deriva autoritaria del gobierno francés y desde donde el gobernador español alcanzó acuerdos con miembros de la alta nobleza como los duques de Vendôme y de Bouillon, la duquesa de Chevreuse, el conde de Saint-Ibal y, más tarde con el propio Condé20. En febrero de 1649, el archiduque Leopoldo Guillermo llegó incluso a enviar como emisario ante el Parlamento de París a José Arnolfini para proponer un acuerdo de paz ${ }^{21}$, mientras que Felipe IV financiaba el envío de efectivos militares y navales para sostener en Burdeos al parti de l'Ormée, un movimiento radical de tintes republicanos y que contaba en sus filas con un nutrido grupo de hugonotes ${ }^{22}$.

El conflicto contra Francia permitió a la Monarquía Hispánica presentarse en el escenario internacional como la defensora de los ordenamientos jurídicos y constitucionales tradicionales frente a toda deriva autoritaria. El recurso al perdón y

the Struggle for the World Supremacy, 1585 1713. Londres, 1997, pp. 105-144. Por su parte, Manuel Rivero en su análisis sobre el gobierno del conde de Oñate tras la restauración de la autoridad real en Nápoles y la posterior recuperación de los Presidios toscanos, gran parte de los cuales habían sido arrebatados por Francia en 1646, señala taxativo: «La hegemonía española no fue suplantada por la francesa, al menos en Italia». RIVERO RODRÍGUEZ, M.: "Como un cordero entre lobos: La recuperación de la iniciativa política y diplomática española en Italia (1648-1664)», en SANZ CAMAÑES, P. (ed.): Tiempo de cambios. Guerra, diplomacia y politica internacional de la Monarquía Hispánica (1648-1700). Madrid, 2012, p. 366.

19. Carta del conde de Peñaranda a Don Luis de Haro, Munster, 18 de mayo de 1648, en BNM, Mss 1040, f. 118.

20. SÉRÉ, D.: La paix des Pyrénées. Vingt-quatre ans de négociations entre la France et l'Espagne (1635-1659). París, 2007, pp. 151-154.

21. Idem, pp. 173-175. Véanse los sugerentes planteamientos en torno a la figura de José de Arnolfini como expresión del nuevo posicionamiento de la Monarquía tras Westfalia en JOVER ZAMORA, J. M. y LÓPEZ-CORDÓN CORTEZO, M. V.: «La imagen de Europa y el pensamiento político internacional», en El siglo del Quijote, 1580-1680, tomo XXVI-l de la Historia de España fundada por R. Menéndez Pidal. Madrid, pp. 353-522.

22. El monarca solicitó asimismo a su embajador en Londres, Alonso de Cárdenas, que hiciese las gestiones pertinentes para que Cromwell se involucrase en la contienda en defensa de los rebeldes bordeleses, Carta de Felipe IV a Alonso de Cárdenas, Madrid el 18 de noviembre de 1653, en Archives Générales du Royaume de Bruxelles (AGRB), Secrétairerie d'État et de Guerre (SEG), leg. 256, f. 276.

Ediciones Universidad de Salamanca / @®@@ Stud. his., H. ${ }^{a}$ mod., 41, n. 1 (2019), pp. 189-230 
el mantenimiento de las inmunidades y libertades en aquellos dominios que, como Cataluña, Nápoles o Sicilia, se habían levantado contra la autoridad del soberano constituían la expresión palmaria de su respeto hacia las formas de gobierno propias de cada comunidad local, lo que ayudó de manera notable a disipar la pretendida aspiración de los Habsburgo a la monarquía universal y su deseo de imponer el catolicismo por la fuerza de las armas. La Monarquía Hispánica no tardó en presentarse como el principal sostén de la causa republicana no sólo en Francia, como hemos visto que ocurrió en Burdeos, sino también en las Provincias Unidas, donde las negociaciones de paz en Westfalia impulsaron sus estrechas relaciones con el partido de los regentes y con la provincia de Holanda contra la deriva soberanista del belicoso Príncipe de Orange que contaba con el apoyo de Francia. El enlace matrimonial de Guillermo II con los Estuardo y los vínculos que Carlos I mantenía con Francia, facilitaron asimismo el paulatino acercamiento de la Monarquía Hispánica hacia la causa republicana durante la guerra civil que asoló Inglaterra. Tras la decapitación del rey, Felipe IV se convirtió en el primer monarca en reconocer que, como señalara su embajador, Alonso de Cárdenas, durante su entrada oficial en Westminster en diciembre de 1650: «la autoridad y soberanía reside en el Parlamento de la república de Inglaterra ${ }^{23}$. Poco tiempo antes, en septiembre de ese mismo año, el embajador español en La Haya, Antoine Brun, preocupado por el golpe militar realizado por el Estatúder Guillermo II contra la ciudad de Ámsterdam, que ponía en peligro el tratado de paz alcanzado en Münster, animaba a Cárdenas en estos términos a alcanzar un acuerdo con Cromwell:

así será preciso prevenirnos por esta parte y entrar al fin en alguna confederación con aquel Parlamento de que creo que se holgará la provincia de Holanda y quizá también querrá entrar en la dicha confederación a que la iré animando debajo de mano cuando me veré obligado a no poder más con el príncipe de Orange para desviar sus pláticas con Francia ${ }^{24}$.

Esta misiva constituye una prueba elocuente de cómo, para mediados del siglo XVII, las cuestiones confesionales, que habían sido una de los principales instrumentos de movilización militar desde el estallido de la Reforma, se habían desdibujado. La consolidación de las buenas relaciones entre la Monarquía Hispánica y las principales potencias protestantes, que ya se había puesto de relieve previamente gracias a los acuerdos parciales alcanzados con las ciudades hanseáticas, el duque de Sajonia o el rey de Dinamarca, parecía quebrar uno de los principales axiomas

23. AllOZA, A.: «La Monarquía Católica y la Commonwealth of England», en HERRERO SÁNCHEZ, M. (ed.): Republicas y republicanismo en la Europa Moderna (siglos XVI-XVIII). Madrid, 2017, p. 367.

24. Carta de Antoine Brun a Alonso de Cárdenas, La Haya a 9 de septiembre de 1650, en AGS, EEH, leg. 8644. 
MANUEL HERRERO SÁNCHEZ

LAS REPÚBLICAS MERCANTILES DE GÉNOVA Y LAS PROVINCIAS UNIDAS

ANTE EL CONFLICTO HISPANO-FRANCÉS POR LA HEGEMONÍA (1635-1659)

de la política exterior del monarca católico que había actuado además como una palanca para legitimar el aumento de la presión fiscal y convertir sus dominios en un espacio de acogida para el exilio católico ${ }^{25}$. A la luz de estas evidencias, conviene revisar los recientes planteamientos que tienden a revitalizar el peso de las cuestiones religiosas en la política exterior europea durante la segunda mitad del XVII, como acreditaría la revocación del Edicto de Nantes por parte de Luis XIV en 1685 y la alianza de las potencias marítimas con la llegada de Guillermo III al trono de Inglaterra en 1688 tras la nueva y definitiva expulsión de los Estuardo ${ }^{26}$. Como ha señalado con acierto Charles-Édouard Levillain, este tipo de narrativas, de marcada raigambre whig, parte de una ecuación simplista que establece un enlace automático entre catolicismo y absolutismo y entre protestantismo y gobierno representativo ${ }^{27}$. No olvidemos que en su acceso al trono de Inglaterra, Guillermo III contó con el inestimable sostén de los Habsburgo cuya alianza con las potencias protestantes era compatible con su acreditado marchamo católico, como atestiguaban la retórica eucarística ligada a la dinastía, el impulso de la cruzada contra el imperio otomano tras el segundo sitio de Viena o el firme apoyo en favor del papado frente a la agresiva política galicana del rey Cristianísimo ${ }^{28}$. La pérdida de peso de las anteriores alianzas confesionales había quedado sancionada con anterioridad, como demostraron de manera fehaciente los tres enfrentamientos navales entre las Provincias Unidas e Inglaterra, entre 1652 y 1674, o el hecho de que en las paces de Westfalia se hubiesen resuelto los principales conflictos que afectaban hasta el momento a las potencias protestantes y católicas mientras que permanecieron activos los enfrentamientos entre los soberanos luteranos de Suecia y Dinamarca o entre Francia y la Monarquía Hispánica, los dos principales reinos católicos.

25. RUIZ IBÁÑEZ, J. J. y PÉREZ TOSTADO, I. (coords.): Los exiliados del rey de España. Madrid, 2015.

26. ONNEKINK, D. (ed.): War and Religion after Westfalia, 1648-1713. Farnham, 2009.

27. LEVILLAIN, C.-E.: Vaincre Louis XIV. Angleterre-Hollande-France. Histoire d'une relation triangulaire, 1665-1688. París, 2010. Véase también HERRERO SÁNCHEZ, M.: «Paz, razón de estado y diplomacia en la Europa de Westfalia. Los límites del triunfo del sistema de soberanía plena y la persistencia de los modelos policéntricos (1648-1713)», Estudis. Revista de Historia Moderna, 41, 2015, pp. 43-65.

28. Cristina Bravo Lozano está llevando a cabo un estudio en torno al papel central jugado por las capillas que los embajadores españoles mantuvieron en Londres, La Haya y Hamburgo como espacio de protección de las comunidades católicas ante los aliados protestantes de la corona. Al respecto véase una primera contribución en BRAVO LOZANO, C.: «¿Antemural de la fe o tierras de misión?: Reflexiones en torno al Norte y la proyección confesional de la monarquía de España, 1665-1700», en GARCÍA MARTÍN, P., QUIRÓS ROSADO, R. y BRAVO LOZANO, C. (coords.): Antemurales de la Fe: conflictividad confesional en la Monarquía de los Habsburgo, 1516-1714. Madrid, 2015, pp. 213-240.

Ediciones Universidad de Salamanca / అ@@ Stud. his., H. ${ }^{a}$ mod., 41, n. 1 (2019), pp. 189-230 
MANUEL HERRERO SÁNCHEZ

LAS REPÚBLICAS MERCANTILES DE GÉNOVA Y LAS PROVINCIAS UNIDAS

ANTE EL CONFLICTO HISPANO-FRANCÉS POR LA HEGEMONÍA (1635-1659)

En efecto, el acuerdo de paz alcanzado entre el Emperador y los reyes de Francia y Suecia en octubre de 1648, del que quedó excluido el monarca Católico, debilitaba también otro de los principales axiomas que habían marcado la política exterior de la Monarquía Hispánica desde la abdicación de Carlos V en 1555: la solidez de los lazos dinásticos entre ambas ramas de la casa de Austria. Las dificultades para coordinar los esfuerzos militares tras la declaración de guerra de Francia en 1635 evidenciaban el enfriamiento de las buenas relaciones entre Madrid y Viena, que alcanzaría su punto culminante durante la fase final de la privanza de Olivares. Los deseos del Emperador de actuar como mediador en los levantamientos de Cataluña y Portugal, para cuya resolución abogaba por el recurso a la vía de la clemencia tan cara a los Habsburgo, fueron cortados de raíz por el valido ${ }^{29}$. La caída del conde duque impulsó la revitalización de las obligaciones mutuas que ligaban al monarca Católico con el Emperador por sus dominios en Flandes y en el Franco Condado mediante el envío a la Dieta de Ratisbona de un delegado del Círculo de Borgoña ${ }^{30}$. Aunque el acuerdo de paz de Westfalia puso coto a la colaboración militar entre los Habsburgo, a lo largo de la segunda mitad del siglo XVII, la Monarquía Hispánica siguió apostando por robustecer los lazos de dependencia jurisdiccional con el Imperio. ${ }^{31}$ El mantenimiento de la política de matrimonios mixtos (como evidencian los enlaces entre Felipe IV y su sobrina Mariana de Austria en 1649 o el de la hija de ambos, la infanta Margarita, con el Emperador Leopoldo I en 1666) y la acción concertada del gobernador español en los Países Bajos con los sucesivos embajadores españoles en La Haya y en Viena, que contaron con el notable sostén propagandístico de François-Paul Lisola, abrieron el camino para volver a estrechar los vínculos entre los Habsburgo. La firma del tratado de La Haya en 1673, por

29. En octubre de 1641, el embajador imperial, marqués de Grana, señalaba: «que porque los accidentes de España daban mucha pena y cuidado a Su Majestad Cesárea particularmente los de Cataluña aconsejaba a Vuestra Majestad usase la clemencia con aquellos vasallos perdonándoles para matar aquel fuego ofreciendo Su Majestad Cesárea quedar por fiador de lo que se les ofreciere para que esto los asegure en la desconfianza que tendrán del perdón y en el puntual cumplimiento de lo que se les prometiere pues de ningún otro príncipe puede Vuestra Majestad ni ellos fiar lo que de Su Majestad Cesárea cuyo poder y plenipotencia traía para que se pudiesen usar de su interposición como pareciese.» Consulta del Consejo de Estado sobre la entrada del embajador imperial en Madrid, Madrid a 19 de octubre de 1641, AGS, Estado, leg. 2342.

30. En calidad de plenipotenciario español en las paces de Westfalia, Saavedra Fajardo señalaba a finales de 1643: «Cuánto importaba que como príncipe del Imperio se sirva Vuestra Majestad de nombrar por la casa y círculo de Borgoña un sujeto de muchas sangre y calidad como se ha hecho por el pasado que asista allí por plenipotenciario de VM y tendría por conveniencia que fuese nacido en los estados de Flandes o en Alemania con conocimiento de estas lenguas.» Carta de Saavedra Fajardo a Felipe IV, Munster a 20 de noviembre de 1643, en AGS, Leg. 2345.

31. SCHILLINGER, J.: «La Franche-Comté et les enjeux diplomatiques du Cercle de Bourgogne à la Diète de Ratisbonne 1667-1674», Revue d'Histoire Moderne et Contemporaine, XXXIX, (1992), pp. 531-550. 
el que el Emperador se sumaba al duque de Lorena y al monarca Católico en un sólida alianza ofensiva con las Provincias Unidas, permitió frenar la agresión francobritánica contra la república e inauguró una estrecha alianza que se quebraría tan sólo con la muerte de Carlos II en $1700^{32}$.

Se trataba de una trayectoria totalmente diferente a la experimentada por la Francia de Luis XIV con relación al Sacro Imperio. El rey Cristianísimo, que había sido el principal sostenedor de la plena soberanía de los príncipes territoriales alemanes y que se había postulado como defensor de las libertades germánicas contra el Emperador, como acreditaría la conformación de la Liga del Rin en 1658, se inclinó por romper los lazos de vasallaje que le ligaban al Imperio. De este modo, tanto los tres obispados de Metz, Toul y Verdún, cuya posesión fue sancionada por la firma de la paz de Westfalia, como los sucesivos territorios que iría arrancando al monarca Católico en sus dominios borgoñones a lo largo de la segunda mitad del siglo XVII, pasaron a incorporarse directamente a la jurisdicción del reino de Francia $^{33}$. La apuesta por la plena soberanía del monarca sobre su territorio le animó asimismo a mostrar un creciente desapego con respecto a los escasos regímenes republicanos con los que Francia había mantenido hasta el momento una estrecha correspondencia. Ya durante las negociaciones de Westfalia, el representante francés en el congreso había instigado a los Cantones Suizos y a las Provincias Unidas a exigir la rescisión de los lazos de dependencia con respecto al Emperador y había adoptado una actitud negligente hacia las ciudades libres imperiales y hacia las ligas urbanas como la Hansa. Se trataba de una postura que contrastaba con la adoptada por la Monarquía Hispánica que, mediante un acuerdo de alianza firmado en $1647^{34}$, facilitó la acción de los hombres de negocios de dichas ciudades en los puertos bajo la jurisdicción del monarca Católico, además de ofrecer un trato preferente a los enviados de esta agrupación de repúblicas autónomas en la corte de $\mathrm{Madrid}^{35}$. El sostén ofrecido a los cantones suizos más débiles, que desconfiaban de la situación de desamparado que podría derivarse de la ruptura con la legislación imperial, constituía también una prueba de que la Monarquía Hispánica, al igual que el Emperador, se

32. HERRERO SÁNCHEZ, M.: «La Monarquía Hispánica y el Tratado de La Haya de 1673», en LECHNER, J. y BOER, H. der (eds.): España y Holanda. Ponencias leidas durante el quinto coloquio hispanobolandés de historiadores, Diálogos Hispánicos n⿳16. Amsterdam, 1995, pp. 103-118; LEVILLAIN, C. E.: Le Procès de Louis XIV: Une guerre psychologique. París, Tallandier, 2015.

33. BRAUN, op. cit., pp. 41-42.

34. WELLER, T.: «Las repúblicas europeas y la Paz de Westfalia: la representación republicana en las negociaciones de Münster y Osnabrück», en HERRERO SÁNCHEZ, M. (ed.): Republicas y republicanismo en la Europa Moderna (siglos XVI-XVIII). Madrid, 2017, pp. 329-347.

35. WELLER, T.: «Merchants and Courtiers. Hanseatic Representatives at the Spanish Court in the Seventeenth Century», Dimensioni e problemi della ricerca storica, 1, 2014, pp. 73-98. 
presentaba como la garante de aquellas repúblicas urbanas que veían peligrar su autonomía $^{36}$. La propia estructura policéntrica de la monarquía facilitaba el establecimiento de una variada gama de espacios de representación diplomática con la Confederación Helvética que, junto a una delegación con limitadas atribuciones en Madrid, se canalizaba principalmente desde del ducado de Milán ${ }^{37}$. Una situación que contrastaba con el trato humillante mostrado por Luis XIV hacia la embajada de los 13 Cantones suizos que visitó París en 1663 y que parecía inaugurar la política de exteriorización pública de la plena autonomía de la monarquía francesa con respecto a las repúblicas mercantiles que culminaría en 1672 con la agresión militar contra Génova y las Provincias Unidas.

\section{FORMAS DE NEGOCIACIÓN, AGENTES Y CONFLICTOS INTERNOS EN LAS RELACIONES DIPLOMÁTICAS ENTABLADAS ENTRE LAS REPÚBLICAS MERCANTILES DE GÉNOVA Y LAS PROVINCIAS UNIDAS Y AMBAS MONARQUÍAS}

Desde principios del siglo XVI, tanto el rey Cristianísimo como el monarca Católico habían hecho todos los esfuerzos posibles por atraerse el favor de las principales repúblicas urbanas debido a su capacidad para proveerles de toda una serie de recursos navales y de servicios financieros fundamentales para inclinar la balanza de uno u otro lado en el permanente conflicto militar que las enfrentaba. Ahora bien, mientras que Francia se decantaba por estimular las pretensiones a la plena soberanía de dichas repúblicas en las escena internacional, la Monarquía Hispánica apostó más bien por favorecer a determinadas familias, agentes o corporaciones a través de todo tipo de prebendas y privilegios para operar en sus mercados o mediante el recurso a la gracia real, del mismo modo que hacía con sus propios súbditos.

Esta diversidad de estrategias reflejaba la diferente naturaleza constitucional de ambas monarquías. El sistema imperial hispánico, en cuyo seno se encontraban algunos de los más dinámicos núcleos urbanos de Europa, y que había llevado a cabo el proceso de expansión ultramarina mediante la creación de nuevas ciudades como principal espacio de negociación con el soberano, sustentaba su capacidad para operar a escala global en un exquisito respeto por la autonomía local. Se trataba de una verdadera monarquía de repúblicas urbanas caracterizada por la fuerte

36. MAISSEN, T.: «Inventing the Sovereign Republic. Imperial Structures, French Challenges, Dutch Models, and the Early Modern Swiss Confederation», en HOLENSTEIN, A., MAISSEN, T. y PRAK, M. (eds.): The Republican Alternative. The Netherlands and Switzerland compared. Ámsterdam, 2008, pp. 125-150.

37. BEHR, A.: «La representación de los Cantones suizos en la corte de España a finales del siglo XVII: un primer acercamiento", Dimensioni e problemi della ricerca storica, 1, 2014, pp. 167-189.

Ediciones Universidad de Salamanca / 요 Stud. his., H. ${ }^{a}$ mod., 41, n. 1 (2019), pp. 189-230 
MANUEL HERRERO SÁNCHEZ

LAS REPÚBLICAS MERCANTILES DE GÉNOVA Y LAS PROVINCIAS UNIDAS

ANTE EL CONFLICTO HISPANO-FRANCÉS POR LA HEGEMONÍA (1635-1659)

competencia y colaboración entre las distintas corporaciones, ciudades y entidades agregadas en el seno de una misma estructura política ${ }^{38}$. Mientras que el rey Cristianísimo impulsó medidas para favorecer a sus súbditos y acabó por interponer todo tipo de obstáculos para que los hombres de negocios extranjeros pudieran operar en sus mercados, en el seno de la Monarquía Hispánica circularon con facilidad una sorprendente multiplicidad de entramados transnacionales que actuaron como uno de los principales factores de cohesión entre sus dispersos territorios. En buena medida, la autoridad y la capacidad de maniobra del monarca Católico dependían de la relación simbiótica que mantenía con las activas repúblicas urbanas ubicadas tanto dentro como fuera de sus dominios. Esta situación multiplicó los espacios de negociación con unas repúblicas que, lejos de aparecer como una alternativa modernizadora o como el último bastión frente al avance del modelo absolutista, compartían con las ciudades bajos la jurisdicción del monarca católico una misma estructura corporativa y patrimonial de la sociedad y estaban fuertemente ligadas a unas monarquías en las que el poder del soberano se veía limitado por multitud de privilegios y prerrogativas ${ }^{39}$.

La fuerte fragmentación de la soberanía que caracterizaba a estas repúblicas mercantiles, que al igual que había ocurrido en el seno de las principales ciudades europeas habían experimentado un marcado proceso de oligarquización de su elite dirigente, suscitó el estallido de constantes enfrentamientos internos que facilitaron la injerencia de las potencias extranjeras y dieron lugar a constantes alteraciones en el posicionamiento de ambas repúblicas en el escenario internacional. Entre 1635 y 1659, las Provincias Unidas y Génova experimentaron un notable cambio de actitud en las relaciones bilaterales mantenidas hasta el momento con Francia y la Monarquía Hispánica. Mientras que la república ligur se inclinó por adoptar una posición de neutralidad, que ponía en cuestión los sólidos lazos que la unían al monarca Católico desde 1528, el tradicional enemigo holandés acabó por convertirse, tras la firma de la paz de Münster, en el principal socio de la Monarquía Hispánica

38. HERRERO SÁNCHEZ, M.: «La Monarquía Hispánica y las repúblicas europeas. El modelo republicano en una monarquía de ciudades», en HERRERO SÁNCHEZ, M. (ed.): Repúblicas y republicanismo en la Europa Moderna (siglos XVI-XVIII). Madrid, 2017, pp. 273-328; BENIGNO, F.: «Una repubblica monarchica? Riflessioni su teorie politiche e pratiche di governo nella Spagna del Seicento», en PARDOS, J. et al (eds.): Historia en fragmentos. Estudios en homenaje a Pablo Fernández Albaladejo. Madrid, 2017, pp. 387-396.

39. HERRERO SÁNCHEZ, M. (ed.): Repúblicas y republicanismo en la Europa Moderna (siglos XVI-XVIII). Madrid, 2017. En este volumen se pone el acento en la pluralidad de los lenguajes republicanos y se cuestionan los clásicos dualismos reduccionistas que, en línea con el enfoque atlántico y anglosajón del republicanismo propio de la Escuela de Cambridge, establecen fuertes diferencias entre repúblicas y monarquías. Planteamiento, este último, que queda recogido en los dos volúmenes editados por VAN GELDEREN, M. y SKINNER, Q. (eds.): Republicanism: a Shared European Heritage. 2 vols., Cambridge, 2002.

Ediciones Universidad de Salamanca / @®@@ Stud. his., H. ${ }^{a}$ mod., 41, n. 1 (2019), pp. 189-230 
junto a la que puso en pie el sistema de alianzas internacionales destinado a frenar la política expansionista de Luis XIV.

La negociación con las repúblicas mercantiles parecía verse obstaculizada por un laberinto de intereses contrapuestos y por las múltiples instancias con las que era necesario tratar para alcanzar cualquier tipo de acuerdo. Sin embargo, había sido precisamente este tipo de conflictos internos y la necesidad de preservar su autonomía frente a la política expansionista de los estados vecinos, lo que explica el impulso experimentado por la vía de la negociación en el seno de estas poderosas estructuras urbanas que, no en vano, habían sido las primeras en enviar y mantener legaciones permanentes en el exterior. Además, el carácter colegiado de sus órganos de gobierno y la multiplicidad de instancias soberanas impulsaron un proceso de institucionalización de la actividad diplomática y toda una serie de mecanismos de supervisión de sus representantes en el exterior que acabaron por ser imitados por las principales monarquías ${ }^{40}$. Esta capacidad negociadora sumada a la necesidad de garantizar un equilibrio de poderes entre las principales potencias, del que dependía la propia supervivencia de dichas repúblicas, explican el activo papel de intermediación que ejercieron en la resolución de los principales conflictos militares mientras que su apuesta por las negociaciones colegiadas impulsaron el sistema de congresos multilaterales que, a partir de Westfalia, acabaría por imponerse ${ }^{41}$. Es precisamente en este contexto en el que debemos ubicar los esfuerzos desplegados primero por Venecia y con posterioridad por las Provincias Unidas para interceder en el conflicto hispano-francés o el hecho de que, a lo largo de la segunda mitad del siglo XVII, la república neerlandesa se convirtiese en el principal espacio de negociación diplomática del continente. Así lo atestiguan los numerosos congresos internacionales que se desarrollaron en su territorio y el hecho de que los principales tratados de paz o de alianza tuviesen por escenario ciudades neerlandesas como Nimega, Rijswijk, La Haya o Utrecht.

Las repúblicas mercantiles disponían asimismo de otro tipo de agentes que, como los cónsules, velaban por garantizar el cumplimiento de los privilegios arrancados en los acuerdos de navegación y comercio o por facilitar la acción de sus efectivos navales y de sus numerosos convoyes. $\mathrm{Al}$ respecto resulta ilustrativo el hecho de que, una vez ratificada la paz con el monarca Católico, las Provincias Unidas tardasen menos de dos semanas en desplegar un tupido tejido consular en

40. FRIGO, D.: «Politica estera e diplomazia: figure, problema e apparati», en GRECO, G. y ROSA, M. (eds.): Storia degli antichi stati italiani. Roma, 1997, pp. 117-161; HERRERO SÁNCHEZ, M.: «Republican Diplomacy and the power balance in Europe», en ALIMENTO, A. (ed.): War, trade and neutrality. Europe and the Mediterranean in seventeenth and eighteenth centuries. Milán, 2011, pp. 23-40.

41. CHANET, J.-F. y WINDLER, C. (eds.): Les resources des faibles. Neutralités, sauvegardes, accommodements en temps de guerre (XVIe-XVIIe siécles). Rennes, 2009.

Ediciones Universidad de Salamanca / 요 Stud. his., H. ${ }^{a}$ mod., 41, n. 1 (2019), pp. 189-230 
los principales puertos de la monarquía mientras que el envío de un representante diplomático oficial a Madrid, con el mero título de residente, se demoró, a pesar de la protestas de la corona que contaban con un embajador permanente en La Haya, nada menos que ocho años ${ }^{42}$. Los entramados diplomáticos de dichas repúblicas adolecían de una serie de limitaciones que dificultaban la acción de sus representantes. El enmarañado sistema de toma de decisiones dotaba de un escaso margen de maniobra a sus diferentes legaciones en el exterior ${ }^{43}$ que sufrían de una posición subsidiaria en el rígido sistema protocolario cortesano en el que debía desenvolverse que, no lo olvidemos, exigía, además, el desembolso de cuantiosas sumas de dinero sustancialmente superiores a las partidas que se les asignaban. El desplazamiento al exterior suponía, asimismo, un alejamiento de los principales espacios de toma de decisión en sus respectivas repúblicas y era considerado en ocasiones como una especie de exilio, lo que hizo necesario recurrir a mecanismos compulsivos para poder cubrir los puestos que quedaban vacantes.

En estas condiciones, y habida cuenta del interés por atraerse el apoyo de estas repúblicas mercantiles, tanto Francia como la Monarquía Hispánica apostaron por remitir representantes diplomáticos con amplias atribuciones y capaces de negociar sobre el terreno. En Génova, aunque el embajador español vio cómo se cercenaban paulatinamente gran parte de los privilegios de los que gozaba, hasta principios de la década de 1680 el monarca católico era el único soberano que contaba con un representante permanente en la república ${ }^{44}$. Por el contrario, tras la llegada del primer embajador español ante los Estados Generales en 1649, La Haya se convirtió

42. HERRERO SÁNCHEZ, M.: «La red diplomática de las Provincias Unidas en la Corte española durante la segunda mitad del siglo XVII», Dimensioni e problemi della ricerca storica, 1, 2014, pp. 131-163.

43. En 1650, el embajador español en Venecia solicitó al representante del rey en La Haya una relación pormenorizada del complejo sistema de toma de decisiones: «Los que han escrito el gobierno de todos los Príncipes y Repúblicas he visto que hacen tantos errores en lo que refieren de aquellas partes de donde yo tengo individual noticia que deseándola del modo con que hoy se gobiernan ahí y con qué oyen y responden a los ministros de otros príncipes suplico a Vuestra Señoría que, si los negocios permitieren algunas otras desembarazadas, me haga merced de una Relación de todo lo que le pareciere que merece reparo.» Carta del marqués de la Fuente a Antoine Brun, Venecia a 16 de diciembre de 1650, en AGS, Estado, EEH, Leg. 8725. En línea con lo que requería el marqués de la Fuente, en el Consejo de Estado en Madrid se elaboró un detallado índice en el que se ofrecía información sobre algunas de las instituciones y corporaciones que operaban en las Provincias Unidas, Índice de documentos de Inglaterra y Holanda, en Archivo Histórico Nacional (AHN), Estado, libro 697. Véase también GREVER, J. H.: «The Structure of Decision-Making in the States General of the Dutch Republic 16601668», Parliaments, Estates and Representation, 2, 1982, pp. 125-152.

44. Aunque la república aceptó en 1636 la presencia de un agente francés, no será hasta 1682 cuando por vez primera Francia remita un enviado extraordinario, Pidon de Saint Olon. VITALE, V.: La diplomazia genovese. Milán, 1941, pp. 309-315.

Ediciones Universidad de Salamanca / అ@@ Stud. his., H. ${ }^{a}$ mod., 41, n. 1 (2019), pp. 189-230 
en el escenario de constantes altercados entre los representantes diplomáticos de ambos monarcas que recurrieron al soborno o la difusión de panfletos y libelos para atraerse a los diferentes grupos de interés que operaban en la república. La correspondencia diplomática de los sucesivos representantes del monarca católico en las Provincias Unidas está trufada de constantes quejas sobre las dificultades que entrañaba «ajustar ninguna materia con principado que se compone de muchas cabezas», como de forma gráfica señalaba desde Venecia el marqués de la Fuente a su homólogo en La Haya, Antoine Brun ${ }^{45}$.

A pesar de estos lamentos en torno a la complejidad que suponía negociar con estructuras políticas caracterizadas por la fuerte fragmentación de la soberanía, que constituían más bien la expresión de una retórica cortesana destinada a ensalzar sus dotes negociadoras y su prudencia a la hora de moverse con habilidad en el laberinto diplomático, los representantes del monarca Católico en el exterior, al igual que sus homólogos franceses, no tenían demasiadas dificultades para tratar de forma simultánea con una multiplicidad de corporaciones y agentes particulares con capacidad para negociar y alcanzar acuerdos parciales. Como acreditan los más recientes trabajos en torno a lo que ha venido a denominarse como New Diplomatic History, durante la Edad Moderna la naturaleza fuertemente fragmentada de unas estructuras estatales caracterizadas por la existencia de una multiplicidad de corporaciones con derechos privativos explica que no existiese un único titular de la acción diplomática ${ }^{46}$. La diplomacia operaba en un sistema multipolar de negociaciones en el que resultaba incluso difícil establecer una barrera nítida entre las relaciones exteriores y las interiores como atestigua la existencia en el seno de la Monarquía Hispánica de numerosas embajadas de agentes locales, procuradores o síndicos enviados por determinadas ciudades y territorios bajo la jurisdicción del monarca Católico a la corte. Como hemos visto para el caso de la Confederación Helvética o las ciudades hanseáticas, estas legaciones no eran tan diferentes de la

45. Carta del marqués de la Fuente, embajador español ante la Serenísima, a Antoine Brun, Venecia a 21 de enero de 1650, en AGS, EEH, Estado, leg. 8725. A su vez, el propio Brun expresaba su solidaridad con de la Fuente recurriendo al mismo símil: «a quien compadezco entrañablemente bien conociendo lo que es de tratar con repúblicas que, aquí también hay una fiera bestia de cien cabezas como allí y cada día se habla de alguna novedad y disensión.» Carta de Antoine Brun al embajador español en Venecia, marqués de la Fuente, La Haya, 16 de junio de 1650, en AGS, EEH, Estado, leg. 8644.

46. Al respecto son clarificadores los trabajos de LAZZARINI, I.: «Storia della diplomazia e International Relations Studies fra pre-e post-moderno», Storica, 65, XXII, 2016, pp. 9-41; FRIGO, D.: «Politica e diplomazia. I sentieri della storiografia italiana», en SABBATINI, R. y VOLPINI, P. (eds.): Sulla diplomazia in età Moderna. Politica, economica, religione). Milán, 2011, pp. 35-59 o WATKINS, J., «Towards a New Diplomatic History of Medieval and Early Modern Europe», Journal of Medieval and Early Modern Studies, 38, 2008, pp. 1-14.

Ediciones Universidad de Salamanca / అ@@ Stud. his., H. ${ }^{a}$ mod., 41, n. 1 (2019), pp. 189-230 
MANUEL HERRERO SÁNCHEZ

LAS REPÚBLICAS MERCANTILES DE GÉNOVA Y LAS PROVINCIAS UNIDAS

ANTE EL CONFLICTO HISPANO-FRANCÉS POR LA HEGEMONÍA (1635-1659)

variada tipología de representantes que actuaban en Madrid al servicio de estas repúblicas ${ }^{47}$. A la hora de negociar con otras potencias o al objeto de alcanzar acuerdos o entablar alianzas operaban numerosos niveles de interacción y entraba en acción una enorme variedad de agentes, más allá de la ya de por sí compleja maraña de embajadores, residentes o enviados oficiales. Esta diplomacy from below, en palabras de Morieux ${ }^{48}$, nos obliga a poner el foco en la enorme variedad de espacios de mediación y canales de información, en la importancia crucial de la diplomacia informal o en los mecanismos de patronazgo y clientelismo ${ }^{49}$.

Toda negociación efectiva con las Provincias Unidas tanto del rey de Francia como del monarca Católico no podía contar tan sólo con la acción de sus respectivos representantes diplomáticos en La Haya y todavía menos, como hemos señalado, con la de los sucesivos delegados remitidos por los Estados Generales a París o a Madrid que carecían de suficientes atribuciones para alcanzar cualquier tipo de acuerdo ${ }^{50}$. En dichas negociaciones entraban asimismo en escena otros muchos actores cuya naturaleza y relevancia dependía del asunto a tratar. De este modo, las Provincias Unidas desplegaban una miríada de delegados que no trabajaban necesariamente de manera coordinada con el representante diplomático oficial de la república en Madrid o con el enviado del Príncipe de Orange y que, a su vez, entraban en contacto con una multiplicidad de corporaciones y de espacios de representación que escapaban

47. Véase al respecto el proyecto que dirige en la actualidad Ida Mauro desde la Universidad de Barcelona bajo el título: Hablar a la oreja del rey. Historia comparada de las legaciones de los súbditos en la corte de la Monarquía de España (XVI-XVII). Para el caso de las delegaciones remitidas por las ciudades lombardas en Madrid es fundamental el trabajo de ÁLVAREZOSSORIO ALVARIÑO, A.: «Pervenire alle orecchie della Maestà: el agente lombardo en la corte madrileña», Annali di Storia moderna e contemporánea, 3, 1997, pp. 173-223. A modo de ejemplo, en el artículo 7 del decreto de gracia y perdón emitido por Juan José de Austria tras sofocar la revuelta de Nápoles reglamentaba las característica que la delegación de dicha ciudad podía enviar ante el rey Católico: «Vogliamo e concediamo a detta fidelis Città che posa tener agente in Madrid con mutarsi ogni tre anni eligendosi una volta per li seggi de Nobili e un'altra volta per il fidelis Popolo per supplicare a Sua Maestà tanto per l'osservanza di detti privilegii e gratie concesse quanto por qualsivoglia altra causa.», Cédula de Juan José de Austria en nombre de Felipe IV en la que concede al pueblo de Nápoles indulto y reducción de algunas gabelas con otras gracias. Nápoles a 11 de abril de 1648, en BNM, Mss, 2379, fol. 97.

48. MORIEUX, R.: «Diplomacy from Below and Belonging: Fishermen and CrossChannel Relations in the Eighteenth Century», Past E Present, 202, 1, 2009, pp. 83-125.

49. KEBLUSEK, M. y VERA NOLDUS, B.: Double Agents. Cultural and Political Brokerage in Early Modem Europe. Leiden-Boston, 2011; CARRIÓ-INVERNIZZI, D. (dir.): Embajadores culturales: transferencias y lealtades de la diplomacia española de la Edad Moderna. Madrid, UNED, 2016.

50. Las Provincias Unidas se inclinaban más bien por el envío de embajadas extraordinarias, que en muchas ocasiones eran colectivas, para abordar cuestiones puntuales o expresar su felicitación por determinados acontecimientos. EBBEN M.: Un holandés en la España de Felipe IV. Diario de viaje de Lodewijck Huygens, 1660-1661. Madrid 2010.

Ediciones Universidad de Salamanca / 요 Stud. his., H. ${ }^{a}$ mod., 41, n. 1 (2019), pp. 189-230 
MANUEL HERRERO SÁNCHEZ

LAS REPÚBLICAS MERCANTILES DE GÉNOVA Y LAS PROVINCIAS UNIDAS

ANTE EL CONFLICTO HISPANO-FRANCÉS POR LA HEGEMONÍA (1635-1659)

del limitado ámbito de la corte. Así lo atestiguan las gestiones llevadas a cabo por los sucesivos enviados del Almirantazgo de Ámsterdam encargados de negociar el pago de la deuda contraída por la Monarquía para financiar determinados servicios navales ofrecidos por la república a cambio de partidas de sal andaluza o de concesiones en el tráfico de esclavos, por lo que su negociación se efectuaba tanto en la Corte como en Cádiz o en Sevilla ${ }^{51}$. En otras ocasiones, eran los todopoderosos cónsules que operaban desde alguno de los puertos en los que los hombres de comercio de las Provincias Unidas tenían mayores intereses los que pusieron en pie en la corte una imponente red de sobornos destinada a arrancar crecientes concesiones a la corona para operar en sus mercados ${ }^{52}$. El protagonismo que para las Provincias Unidas tenían los asuntos relacionados con los dominios del rey Católico en los Países Bajos explica la importancia que se le concedió al envío de un residente permanente en Bruselas. Aparte de los numerosos altercados fronterizos no resueltos en el acuerdo de paz alcanzado en $1648^{53}$, entraban en disputa cuestiones aduaneras y resultaba necesario articular políticas comunes de defensa ante la creciente presión militar francesa en la zona. El cargo de residente de los Estados Generales ante el gobernador español en Bruselas recayó, no en vano, en manos de algunos de los más prestigiosos regentes entre los que destacaron determinados familiares del Gran Pensionario, Johan de Witt, como su primo Thomas Sasburg, que fue nombrado en 1656, el mismo año

51. A modo de ejemplo, véanse las negociaciones llevadas a cabo por Francisco de Schonenberg en 1678 para compensar la deuda contraída por la corona para financiar la flota enviada por la república a Mesina dos años antes. Carta de Francisco Schonemberg a Don Juan Ignacio Trujillo sobre las salinas de Cádiz, Madrid, 12 de julio de 1678, en AGS, EEH, Estado, leg. 8490. Francisco de Schonenberg, que era el sobrino del enviado del rey católico en Ámsterdam, el acaudalado sefardita Manuel Belmonte, tras actuar primero como enviado del Almirantazgo, acabó representando los intereses del príncipe de Orange para terminar por actuar en calidad de enviado oficial de los Estados Generales en Madrid. Al respecto véase, HERRERO SÁNCHEZ, M.: «Conectores sefarditas en una Monarquía policéntrica. El caso Belmonte/Schonenberg en la articulación de las relaciones hispano-neerlandesas durante la segunda mitad del siglo XVII», Hispania, LXXVI, 253, 2016, pp. 445-472.

52. El caso del cónsul holandés en dicha ciudad, Jacob Van den Hove, es harto elocuente. Gracias a la mediación de Juan Alonso de Salas, solicitador de Cámara del Consejo Supremo del rey y criatura del influyente negociador de la paz de Münster, el conde de Peñaranda, distribuyó de forma sistemática importantes partidas de cacao y otros productos de lujo entre aquellas personalidades capaces de influir en el ánimo del rey. Carta de Juan Alonso de Salas a Van den Hove, Madrid a 20 de abril de 1650, en Algemeen Rijksarchief Den Haag (ARH), Staten Generaal, 7043 (I). Para más información sobre este tipo de operaciones véase HERRERO SÁNCHEZ, M.: El acercamiento hispano-neerlandés (1648-1678). Madrid, 2000, pp. 77-82.

53. Que no se resolverían hasta la firma del tratado de Ultramosa en 1662, lo que demuestra cómo el establecimiento de fronteras no era competencia exclusiva de un único centro político y que resultaba necesario contar con una multiplicidad de soberanías locales que ponían de relieve cómo la jurisdicción regia se conformaba como el agregado de muchas jurisdicciones y municipios locales.

Ediciones Universidad de Salamanca / అ@@ Stud. his., H. ${ }^{a}$ mod., 41, n. 1 (2019), pp. 189-230 
que la república remitió su primer enviado a la corte de Madrid ${ }^{54}$. En 1671, sería el turno de su hermano, Cornelio de Witt, quien se desplazaría a Bruselas para facilitar la negociación de un acuerdo de asistencia militar en el momento previo al estallido de la guerra contra Francia.

Esta formidable variedad de agentes no era, sin embargo, algo privativo de la manera de negociar de las repúblicas. Como acreditan los ricos fondos documentales de la embajada española en La Haya, el protagonismo de dicha plaza como espacio privilegiado de negociación explica la amplia capacidad de maniobra de la que gozaba el representante del monarca Católico y el elevado grado de institucionalización en comparación con otras legaciones de la corona en el exterior ${ }^{55}$. El embajador español actuaba de forma coordinada con el gobernador de los Países Bajos y estaba obligado a realizar constantes desplazamientos a Flandes ${ }^{56}$, por lo que el eje Bruselas-La Haya, que mantenía una comunicación mucho más fluida que Madrid con las sedes diplomáticas en Londres, Viena o los estados alemanes, actuaba como el verdadero núcleo en la toma de decisiones para los asuntos del norte. Algo semejante a lo que ocurría en lo relativo a las cuestiones italianas con el embajador español en Génova, encargado de coordinar las acciones entre los diferentes territorios del rey en Italia, lo que constituye una expresión palmaria sobre el funcionamiento de una estructura imperial policéntrica. La toma de decisiones se solía articular en torno a las disposiciones adoptadas desde el ámbito local y a través de los múltiples enlaces establecidos entre los dispersos territorios bajo la jurisdicción del rey y no tan sólo sobre las directrices que emanaban de los consejos que operaban desde la lejana corte de Madrid que, en la mayor parte de los casos, acababan por sancionar a posteriori dichas resoluciones.

54. Carta de agradecimiento de Felipe IV a los Estados Generales por enviar un residente a Bruselas, Madrid a 20 febrero de 1657, en ARH, Staten Generaal, leg. 7050.

55. El inventario de dicho archivo, que abarca la documentación emanada por la embajada entre 1649 y 1701, constituye una prueba elocuente de la sorprendente multiplicidad de interlocutores con los que contaban los sucesivos embajadores y secretarios tanto entre el resto de sus homólogos en las demás legaciones europeas, como con los diferentes consejos de la corona en Madrid y, de manera especial, con los representantes del rey en los Países Bajos y con la variada gama de instituciones y corporaciones de la república, incluidas las Compañías de comercio privilegiado, los Almirantazgos o los diferentes municipios. Al respecto véase el catálogo elaborado por LEFÈVRE J. y P.: Inventaire des Archives de l'Ambassade d'Espagne à La Haye. Tongres, 1932.

56. Así se solía fijar en las instrucciones que recibían los embajadores antes de emprender el viaje hacia las Provincias Unidas. No obstante, los recelos que despertaba en Madrid la excesiva autonomía con la que operaban ambos agentes explica que Felipe IV acabase por limitar el tiempo de presencia del embajador de La Haya en los Países Bajos a periodos de no más de ocho días, Felipe IV al embajador en La Haya Esteban de Gamarra en Madrid a 3 agosto de 1661, en AGS, EEH, Estado, leg. 8388.

Ediciones Universidad de Salamanca / 요 Stud. his., H. ${ }^{a}$ mod., 41, n. 1 (2019), pp. 189-230 
Junto al representante del rey en La Haya actuaba un secretario que no formaba parte de su séquito personal y que, en ocasiones, se hacía responsable de forma interina de la embajada. Dicho cargo era elegido entre alguno de los principales servidores del soberano en Flandes y, al igual que el embajador, mantenía una activa correspondencia con el gobernador español y con las principales instituciones, tanto centrales como locales de los Países Bajos. Como pone de manifiesto el caso de Vincent Richard, que ocupó el puesto de forma continuada durante las décadas de 1650 y 1660, el secretario mantenía a su vez vínculos familiares con el cónsul español en Ámsterdam, su hermano Jacques Richard quien, gracias a sus estrechos contactos con las influyentes redes de comerciantes judeo-conversos y sefarditas que operaban en el norte de Europa, recibía información de primera mano sobre el contrabando de los hombres de negocios de la república en el ámbito ultramarino y en los puertos bajo la jurisdicción real ${ }^{57}$. Los entramados transnacionales sefarditas, que actuaron como uno de los principales impulsores del proceso de acercamiento hispano-neerlandés durante las negociaciones de Westfalia, al ser una pieza crucial para inclinar a las todopoderosas Compañías privilegiadas de Comercio del lado de la paz, se convirtieron asimismo en una de las principales piezas de la red diplomática de la Monarquía Hispánica en el norte de Europa. El responsable de la delegación española en Münster, el conde de Peñaranda, pudo disponer de los valiosos servicios financieros y de las redes de contacto ofrecidas por Lopo Ramírez que, en 1654, llegaría a elevar al gobernador español en los Países Bajos, el archiduque Leopoldo Guillermo, una propuesta para la construcción de una sinagoga en Amberes que sería finalmente desestimada al igual que el proyecto del embajador, Antoine Brun, de convertirlo en el cónsul español en Ámsterdam ${ }^{58}$. Las iniciales resistencias de la corona a promocionar a determinados judíos sefarditas en cargos de responsabilidad al servicio del rey Católico acabaron por vencerse como demuestra el nombramiento de Manuel Belmonte y de su hermano Andrés como agentes del rey en Ámsterdam en 1666. La acaudalada red sefardita asentada en las ciudades de Ámsterdam, Hamburgo y Londres se convirtió, a la postre, en la principal proveedora de fondos para financiar las campañas en el norte de Europa y tuvo un protagonismo indiscutible en el buen funcionamiento del asiento de esclavos o en la provisión de pertrechos navales y de recursos fundamentales para sostener la presencia española en Ultramar e impulsar el comercio holandés en la zona ${ }^{59}$.

57. Contamos con una relación pormenorizada sobre este tipo de actividades ilegales remitidas mensualmente al Consejo de Indias por parte de Jacques Richard en Archivo General de Indias (AGI), Indiferente General, leg. 1668.

58. ISRAEL, J. I.: «Lopo Ramirez (David Curiel) and the Attempt to Establish a Sephardi Community in Antwerp in 1653-4», en Empires and Entrepots. The Dutch, The Spanish Monarchy and the Jews, 1585 1713. Londres, 1990, pp. 197-217.

59. HERRERO, «Conectores sefarditas...», op. cit. 
El peso relevante de este tipo de entramados familiares en el proceso de acercamiento y consolidación de las relaciones de la Monarquía Hispánica con las Provincias Unidas ofrece interesantes paralelismos con los procedimientos que habían logrado convertir a la república de Génova, a principios del siglo XVI, en el principal socio mercantil y en uno de los aliados más fiables del monarca Católico. Desde la firma del acuerdo particular de condotta alcanzado entre el armador de galeras, Andrea Doria, y el Emperador Carlos V en 1528, la república ligur se hallaba bajo la protección militar del monarca católico que, como contrapartida, había ofrecido a sus hombres de negocios y a sus asentistas de galeras un espacio de promoción social y de enriquecimiento personal que ligaba de forma estrecha a la elite de la república a los intereses del monarca Católico ${ }^{60}$. Dicho acuerdo vino acompañado de una sustancial reforma constitucional en la república que se tradujo en un cierre oligárquico por el que los cargos políticos quedaban reservados a una serie de familias eminentes que eran las que mayores negocios mantenían con la Monarquía Hispánica ${ }^{61}$. Aunque este sistema sufrió tensiones puntuales en 1547 y 1575, el acuerdo hispano-genovés puso coto a la injerencia de otras potencias en los asuntos de la república y permitió al monarca Católico contar en exclusiva con una serie de recursos navales y financieros insustituibles para mantener su esfuerzo militar y asegurar la comunicación entre sus dispersos territorios ${ }^{62}$. El papel central de Génova para un adecuado funcionamiento del sistema imperial hispánico en el Mediterráneo y su función de nexo conector entre de los dominios del rey en Italia con la península Ibérica y de puerto de entrada para el Camino español a Flandes explica la precaución con la que la corona desplegó un complejo sistema de agentes e informadores destinados a asesorar al embajador del rey Católico en la república ligur. A pesar de que, como hemos señalado, hasta 1682 la Monarquía Hispánica fue la única potencia extranjera que gozaba de una embajada permanente en la república, los intereses de la corona se veían garantizados ante todo por el papel de mediadores jugado por las principales familias de la aristocracia genovesas. Diversas ramas de los

60. HERRERO SÁNCHEZ, M.: «Génova y el sistema imperial hispánico», en ÁLVAREZ-OSSORIO A. y GARCÍA, B. (eds.): La Monarquia de las naciones. Patria, Nación y Naturaleza en la Monarquía de España. Madrid, 2004, pp. 528-562.

61. PACINI A.: I presupposti politici del "Secolo dei Genovesi»: la riforma del 1528. Génova, 1990.

62. Sobre el papel central jugado por los asentistas particulares de galeras véase la excelente tesis doctoral de MARÉCHAUX, B.: Instituciones navales y finanzas internacionales en el Mediterráneo de la época moderna. Los asentistas de galeras genoveses al servicio de la Monarquía Hispánica (1500-1650). Tesis doctoral inédita, Universidad Carlos III, Madrid, 2017. Un estado de la cuestión actualizado sobre lo que Enrique Otte definía como sistema imperial hispano-genovés en HERRERO SÁNCHEZ, M., BEN YESSEF, Y. R., BITOSSI, C. y PUNCUH, D. (eds.): Génova y la Monarquía Hispánica, 1528-1713. Génova, Atti della Società Ligure de Storia Patria, 2011, 2 vols.

Ediciones Universidad de Salamanca / 요 Stud. his., H. ${ }^{a}$ mod., 41, n. 1 (2019), pp. 189-230 
MANUEL HERRERO SÁNCHEZ

LAS REPÚBLICAS MERCANTILES DE GÉNOVA Y LAS PROVINCIAS UNIDAS

ANTE EL CONFLICTO HISPANO-FRANCÉS POR LA HEGEMONÍA (1635-1659)

Doria, los Spinola, los Centurión o los Serra se habían beneficiado del patronazgo regio gracias a los servicios financieros y navales que eran capaces de ofrecer y a su facilidad para operar en el marco de los diversos sistemas jurídicos y monetarios que caracterizaban a la Monarquía Hispánica, por lo que actuaban como un importante factor de cohesión de los dispersos territorios de la corona. Dichos entramados transnacionales, de indiscutible raigambre católica, habían entablado relaciones de parentesco con los miembros del patriciado urbano de las principales ciudades de la Monarquía y habían logrado incluso contraer matrimonios con las más conspicuas casas aristocráticas en Castilla, Nápoles, Sicilia, Milán y los Países Bajos además de alcanzar puestos de responsabilidad en los principales cargos de la administración local y central en los dominios del rey. Todo ello sin romper los lazos que les unían con su ciudad de origen con la que mantenían estrechos vínculos familiares que les permitieron jugar un interesante papel de mediadores entre ambos gobiernos ${ }^{63}$.

La función de intermediación ejercida por estas familias eminentes operaba también en las diferentes legaciones diplomáticas que la república mantenía operativas en los principales dominios del rey católico. Junto a un imponente tejido consular, cuyos privilegios procedían en muchos casos de la Edad Media ${ }^{64}$, la república remitía de manera frecuente embajadas al ducado de Milán o al reino de Nápoles en paralelo a la representación que mantenía de forma permanente en la corte de Madrid donde, no en vano, se negociaban los principales asientos de dineros y de galeras ${ }^{65}$. En estas condiciones, no es sorprendente que los sucesivos embajadores de la república ligur, cuyo escaso peso en el rígido sistema protocolario de la corte les

63. En los últimos años se han multiplicado los trabajos destinados a analizar los mecanismos de promoción y de inserción de estos entramados familiares genoveses en el seno del sistema imperial hispánico: SANZ AYÁN, C.: Un banquero en el Siglo de Oro. Octavio Centurión, el financiero de los Austrias. Madrid, 2015. CARPENTIER B. y PRIOTTI, J.-P.: «La forge instable d'une domination. Les Doria, Gênes et la Monarchie Hispanique (15601606)», en PRIOTTI J.-P. (ed.): Identités et territoires dans les mondes hispaniques (XVIe-XXe siècle). Rennes, 2015, pp. 75-96. BEN YESSEF GARFIA, Y. R.: «Una familia genovesa entre la República y la Monarquía Hispánica: Batista Serra como modelo de la red en un sistema policéntrico entre finales del siglo XVI y la década de 1620», en HERRERO SÁNCHEZ, M. (ed.): Repúblicas y republicanismo en la Europa Moderna (siglos XVI-XVIII). Madrid, 2017, pp. 229-248; HERRERO SÁNCHEZ, M.: «La red genovesa Spínola y el entramado transnacional de los marqueses de los Balbases al servicio de la Monarquía Hispánica», en YUN CASALILLA, B. (ed.): Las redes del Imperio. Élites sociales en la articulación de la Monarquía Hispánica, 1492-1714. Madrid, 2009, pp. 97-133.

64. PETTI BALBI, G.: «Le nazione italiane all'estero», en FRANCESCHI, F., GOLDTHWAITE, R. A. y. MUELLER, R. C. (eds.): Il Rinascimento italiano e l'Europa, Vol. IV, Commercio e cultura mercantile. Treviso-Costabissara, 2007, pp. 397-423.

65. Disponemos de una excelente edición con el contenido de las principales instrucciones y memoriales remitidos por los embajadores de la república en Madrid CIASCA, R.: Istruzioni e relazioni degli Ambasciatori genovesi. Roma, 1951-1968.

Ediciones Universidad de Salamanca / @®@@ Stud. his., H. ${ }^{a}$ mod., 41, n. 1 (2019), pp. 189-230 
mantenía en una situación subsidiaria en comparación con el resto de las legaciones extranjeras desplegadas en Madrid, se viesen obligados a recurrir a los servicios de aquellas familias de la aristocracia genovesa que se hallaban firmemente asentadas en los dominios del rey, con el que entretenían numerosos negocios y para el que ostentaban cargos preeminentes al mando de sus ejércitos, de sus flotas o en el seno de algunos de los principales órganos del entramado polisinodial. En determinadas ocasiones, como acreditan los casos de Bautista Serra o Domenico Grillo ${ }^{66}$, estos particulares se encargaron de forma eventual de los asuntos de la embajada sin renunciar, en ningún caso, a los negocios que mantenían con la corona, lo que no tardó en suscitar vivas críticas por parte de aquellas familias genovesas que no disfrutaban de las mismas prebendas y que acabaron por acusarles de supeditar los intereses de Génova a sus meros intereses particulares y de imponer una política filo-española que, a su modo de ver, era del todo incompatible con la libertad de la república.

\section{GÉNOVA: EL CUESTIONAMIENTO DE LA COLABORACIÓN CON LA MONARQUÍA HISPÁNICA Y LA APUESTA POR LA NEUTRALIDAD}

Desde finales del siglo XVI se fue consolidando en Génova una facción que, desde postulados definidos como «republicanistas» aspiraba a alcanzar idénticas cotas de autonomía que las que disfrutaba la homóloga república de Venecia ${ }^{67}$. La concesión por parte del monarca católico de toda una serie de símbolos de

66. BEN YESSEF GARFIA, Y. R.: «Bautista Serra, un agente genovés en la Corte de Felipe III», Hispania, LXXIII, 2013, pp. 647-672; GARCÍA MONTÓN, A.: «Trayectorias individuales durante la quiebra del sistema hispano-genovés: Domingo Grillo (1617-1687)», en HERRERO SÁNCHEZ, M., BEN YESSEF, Y. R., BITOSSI, C. y PUNCUH, D. (eds.): Génova y la Monarquía Hispánica, 1528-1713. Génova, Atti della Società Ligure de Storia Patria, 2011, pp. 367-384.

67. El contraste entre Génova y Venecia fue difundido por Giovanni Botero que subrayaba las fuertes diferencias entre ambas pues, mientras que los venecianos «attendendo alla mercatanzia reale, si sono arrichiti mediocremente in particolare, ma infinitamente in commune», los genoveses «impiegandosi affatto in cambi, hanno arrichito immoderadamente la facoltà particolari, ma impoverito estremamente l'entrate pubbliche», en BOTERO, G.: Dalla ragion di stato, a cura di L. Firpo, Turín, 1948 [Primera versión 1598], pp. 78-79. Así lo señalaba también el embajador Antonio Ronquillo y Briceño en la relación que remitió a la corona sobre el posicionamiento de los distintos miembros de la elite genovesa con respecto a Francia o España: «El dictamen general es conservar la neutralidad e imaginar esta república tan poderosa como la de Venecia para mantenerla y son pocos los que se libran de esta aprensión.» Carta de Antonio Ronquillo al rey, Génova, 28 de abril de 1648, en AGS, Estado, leg. 3603. Sobre los orígenes del partido republicanista, véase COSTANTINI, C.: «Política e storiografia: l'epoca dei grandi repubblichisti», en La letteratura ligure. La Repubblica aristocrática (1528-1797). Génova/Trento, 1992, Vol. Il, pp. 93-135.

Ediciones Universidad de Salamanca / అ@ఠ Stud. his., H. ${ }^{a}$ mod., 41, n. 1 (2019), pp. 189-230 
distinción, como hábitos de las órdenes militares o títulos de Grande de España, ostentados por determinados miembros de los Doria, como los duques de Tursi, o de los Spinola, como los marqueses de los Balbases, rompía con la teórica unidad de la aristocracia de la república impuesta por las leyes de 1528. A ello venían a sumarse las desproporcionadas partidas dilapidadas en el consumo de objetos de lujo que se consideraban como incompatibles con la teórica virtud republicana y a las que se hacía responsable del abandono de las actividades productivas en favor de las meramente especulativas y financieras y de la total sujeción de la república a los dictámenes de Madrid.

La solidez de la alianza hispano-genovesa había reposado, hasta el momento, en una mutua interdependencia entre la protección militar garantizada de manera eficaz por la Monarquía a cambio de los valiosos servicios financieros, mercantiles y navales ofrecidos por la elite genovesa. Sin embargo, a partir de mediados de la década de 1620 con el estallido de la Guerra de los Treinta Años, el sistema empezó a experimentar importantes tensiones que dieron alas a aquellos sectores que apostaban por revisar dicho acuerdo ${ }^{68}$. A pesar de que en 1625 la Monarquía Hispánica había socorrido con diligencia a la república con motivo de la invasión franco-saboyana, el estallido de la Guerra de Mantua y las negociaciones entabladas por el rey Católico con el duque de Saboya provocaron importantes suspicacias. Se trataba de una situación comprometida para la seguridad de la república a la que vino a sumarse el duro impacto de la bancarrota de 1627 que facilitó la entrada masiva de los hombres de negocios judeo-conversos y rompió con el monopolio ejercido hasta el momento por las principales familias genovesas sobre las finanzas de la corona. Aunque, como ha indicado Carmen Sanz Ayán ${ }^{69}$, los genoveses no sólo mantuvieron negocios conjuntos con los nuevos entramados transnacionales que operaban en el seno de la monarquía Hispánica sino que lograron también ostentar una posición preeminente hasta bien entrado el siglo XVII, es cierto que algunas de las principales familias apostaron por una diversificación de sus actividades financieras y desplazaron gran parte de sus capitales hacia otros mercados, especialmente en Italia pero también en Francia o en el norte de Europa ${ }^{70}$.

El estallido de la guerra entre Francia y la Monarquía Hispánica en 1635 supuso un importante revulsivo en el seno de una república donde, de forma paulatina, había

68. HERRERO SÁNCHEZ, M.: «La quiebra del sistema hispano-genovés (1627-1700)», Hispania, LXV, 219, 2005, pp. 115-152.

69. SANZ AYÁN, C.: Los banqueros y la crisis de la Monarquia Hispánica de 1640. Madrid, 2013.

70. BEN YESSEF GARFIA, Y. R.: «Una transnacionalitat eminentment mediterrània. Diversificació i estratègies en l'entramat familiar genovès dels Serra durant les primeres dècades del segle XVII», Afers: fulls de recerca i pensament, 32, 87, 2017 pp. 391-414. FELLONI, G.: Gli investimenti frianziari genovesi in Europa tra il Seicento e la Restaurazione. Milán, 1971.

Ediciones Universidad de Salamanca / అ@@ Stud. his., H. ${ }^{a}$ mod., 41, n. 1 (2019), pp. 189-230 
ido calando la convicción de que resultaba conveniente mantener una posición de neutralidad incompatible con la postura adoptada hasta entonces hacia el monarca Católico. Al año siguiente, el gobierno genovés, a la vez que aceptaba las credenciales del conde de Siruela en calidad de embajador extraordinario del monarca Católico ${ }^{71}$, remitió a Agostino Centurione a París con el título de enviado extraordinario y, por vez primera, aceptó la presencia de un agente del rey Cristianisimo en la ciudad, el señor de Sabran que, sin embargo, carecía de estatus diplomático. Los intereses de Felipe IV se vieron comprometidos tras la elección como Dux en 1637 de uno de los más destacados partidarios de la facción republicanista, Agostino Pallavicino ${ }^{72}$. A partir de este momento, y hasta la mortífera epidemia de peste de 1657, Génova se embarcó en una política destinada a reforzar su posición de estado plenamente soberano mediante un programa de rearme naval, en el que se primaba la creación de una escuadra pública de galeras frente a los tradicionales asentistas particulares, y mediante una activa política de obras públicas, tanto en el puerto como a través del fortalecimiento del sistema defensivo de la ciudad. Propuestas que bebían de las numerosos libelos y memoriales que, en línea con el título del libro de uno de los más influyentes autores, Bernardo Veneroso, aspiraba a despertar de nuevo el genio ligur y a recuperar la antigua libertad de la república ${ }^{73}$. En uno de estos escritos se animaba a la república a romper la dependencia que tenía con respecto a los mercados hispanos para volver a traficar en el Levante otomano o directamente en el ámbito ultramarino mediante la creación de compañías privilegiadas de comercio ${ }^{74}$.

71. El nombramiento de un miembro de la nobleza para dicho puesto era una prueba del deseo de Madrid de reforzar los lazos con la república en un momento tan delicado, pero no fue bien acogida por el propio interesado que señaló airado: «...las de Génova y príncipes de Italia no suelen ser de aquellas en que Su Majestad, por la mayor parte, ocupa personas de esta clase». Carta del conde de Siruela al rey en Madrid a 4 de julio de 1636, en AGS, Estado, leg. 3636.

72. Sobre los conflictos internos en el seno del patriciado genovés sigue siendo fundamental el trabajo de BITOSSI, C.: Il governo dei magnifici. Patriziato e politica a Genova fra Cinque e Seicento. Génova, 1990.

73. En el prólogo, Veneroso apostaba por convertir Génova en «la città piu maginfica, con superbi acquedotti, più forte, con mura inespugnabili, più gloriosa, con nuove ármate navalli $\mathrm{e}$ più illustre con maravigliose moli nella profondità dell'onde instabili stabilmente fondate», en VENEROSO, G. B.: Genio ligure risvegliato. Génova, 1650. BITOSSI, C.: «Il Genio ligure risvegliato. La potenza navale nel discorso politico genovese del Seicento», en CANTU, F. (ed.): Linguaggi del potere nell'età barocca. Roma, 2009, pp. 81-112. Véase también, KIRK, T.: Genoa and the Sea: Policy and Power in an Early Modern Maritime Republic, 1559-1684. Baltimore, 2013.

74. "Che impegnandosi i genovesi ne traffici di Levante traslaceriano quelli di Spagna e per conseguenza verrano i spagnuoli a mancar di quelle comoditá che cavano dal danaro de Genovesi.» Della necessità che ha la repubblica di Genova di armarsi e del modo di mantenerla armata, Archivio Storico del Comune di Genova (ASCG), Fondo Brignole Sale, Mss. 105-B-7 BS, fols. 327-344.

Ediciones Universidad de Salamanca / 요 Stud. his., H. ${ }^{a}$ mod., 41, n. 1 (2019), pp. 189-230 
MANUEL HERRERO SÁNCHEZ

LAS REPÚBLICAS MERCANTILES DE GÉNOVA Y LAS PROVINCIAS UNIDAS

ANTE EL CONFLICTO HISPANO-FRANCÉS POR LA HEGEMONÍA (1635-1659)

Sin embargo, la celosa defensa de su monopolio por parte de los holandeses y las dificultades para abrirse paso en los nuevos mercados, dieron al traste con las tres compañías puestas en pie entre 1647 y 1655 para traficar en las Indias orientales y Brasil $^{75}$.

La otra línea de actuación de este plan para garantizar la neutralidad y la plena autonomía de la república consistió en apostar por la obtención de un mayor reconocimiento internacional mediante la proclamación en 1637 de la Virgen María como soberana de Génova gracias a los derechos que la Serenísima tenía sobre el reino de Córcega ${ }^{76}$. Aunque Francia, Inglaterra, la Sublime Puerta y, tras el pago de cuantiosos subsidios, el Emperador acabaron por reconocer tales honores regios, tanto el Papa como el Gran Duque de Toscana o Venecia se sumaron a la Monarquía Hispánica en la firme negativa contra tales pretensiones ${ }^{77}$. La tirantez entre los antiguos aliados se tradujo en una espiral de sanciones que tuvo un inmediato reflejo en el ceremonial. Ante la negativa del monarca Católico a que el embajador genovés pudiera cubrirse en su presencia, la república dejó de enviar a la corte de Madrid embajadores ordinarios y limitó de forma contundente los privilegios de los que había gozado hasta el momento el representante del rey en Génova ${ }^{78}$. La cadena de agravios y represalias culminó en 1649 con los altercados que se produjeron con la delegación genovesa en Milán al paso de la futura reina, Marina de Austria, para

75. Ahora bien, como ha señalado recientemente Luca Lo Basso, dichos esfuerzos sirvieron para impulsar la construcción de navíos de alto bordo y para poner en marcha una red de tráfico global que, paradójicamente, estaría detrás de la concesión del asiento de negros a Grillo y Lomelín en 1662 que volvía a ligar a alguna de las principales firmas genovesas con la Monarquía Hispánica. LO BASSO, L.: «De Curaçao a Esmirna. El armamento marítimo en las estrategias económicas de los genoveses durante la segunda mitad del siglo XVII», en HERRERO SÁNCHEZ, M. (ed.): Repúblicas y republicanismo en la Europa Moderna (siglos $X V I-X V I I I)$. Madrid, 2017, pp. 529-553. Véase también SUBRAHMAYAM, S.: «On the significance of Gadflies: the Genoese East India Company of the 1640s», Journal of European Economic History, 17, 3, 1988, pp. 559-581.

76. Como se señalaba en un memorial remitido por el embajador español a Madrid en 1648, la república aspiraba a hacer pública la emancipación con respecto a su antigua protectora y su voluntad de mantener «una neutralidad igual entre las dos corona de España y de Francia», Memorial sin fecha anexo a una Consulta del Consejo de Estado de abril de 1649 sobre varias cartas y documentos enviados por el embajador Antonio Ronquillo, en AGS, Estado, leg. 3604.

77. VITALE, Diplomazia genovese, op. cit., pp. 255-315; CIASCA, R.: «Affermarsi di sovranità della repubblica di Genova nel secolo XVII», Giornale storico e letterario della Liguria, XIV, 1938, pp. 169-170.

78. Que dejó de ser convocado a las procesiones públicas además de suprimirse la tarima que mantenía su silla a la altura de la del Dogo. Para más información sobre la catarata de sanciones protocolarias entre Génova y Madrid véase HERRERO SÁNCHEZ, «La quiebra del sistema...», op. cit. pp. 133-135.

Ediciones Universidad de Salamanca / 요 Stud. his., H. ${ }^{a}$ mod., 41, n. 1 (2019), pp. 189-230 
contraer matrimonio con Felipe IV que la obligaron a embarcarse hacia Barcelona en el puerto de Finale en lugar de por Génova, como era lo habitual ${ }^{79}$.

La presencia española en Finale y la acción de los corsarios al servicio del monarca católico en dicho puerto ponían en cuestión las aspiraciones de la república a ejercer un dominio semejante al que Venecia tenía en el Adriático sobre la costa ligur y estuvieron a punto de provocar la completa ruptura entre los antiguos aliados. Al apresamiento de algunas naves finalinas vinieron a sumarse los nuevos dacios sobre la sal destinada al ducado de Milán y una sucesión de altercados por los saludos que debían prestar determinadas escuadras de particulares genoveses al servicio del rey, por lo que el enérgico gobernador de Milán, el marqués de Caracena, se decantó finalmente por aplicar en 1654 un embargo general sobre los bienes genoveses en los dominios italianos de la corona. Desde Madrid se intentó limitar el excesivo celo del gobernador, que afectaba de manera harto negativa a los miembros de la aristocracia genovesa más afines al monarca Católico y que mayores feudos y propiedades tenían en Nápoles, Sicilia o Milán ${ }^{80}$. Tan rigurosa medida suscitó una enérgica respuesta por parte de la república. Aparte de dictar una serie de disposiciones destinadas a entorpecer las transacciones financieras de los particulares genoveses en los dominios del rey Católico, se desplegó una campaña diplomática dirigida a garantizarse el sostén de los enemigos del rey. La medida llegaba además en un momento muy delicado debido a las crecientes tensiones con Inglaterra que, tras derrotar a las Provincias Unidas en el primero de los sucesivos conflictos navales que enfrentarían a ambas potencias marítimas, parecía cuestionar las buenas relaciones mantenidas hasta el momento con la Monarquía Hispánica, como puso de manifiesto la excelente acogida dispensada por Cromwell al delegado genovés, Ugo Fieschi ese mismo año. Por su parte, el rey Cristianismo se dispuso a aprovechar la coyuntura para revertir la sucesión de los sucesivos fracasos experimentados por las armas francesas en Italia que, tras la recuperación de los Presidios Toscanos y de la plaza de Casale por parte de los efectivos militares españoles, tuvo que ver con desaliento cómo el nuevo intento de invasión de Nápoles por parte del duque de

79. Véanse las dos versiones contrapuestas de tales incidentes en la Carta del embajador español en Génova Antonio Ronquillo sobre el recibimiento de la reina en Génova, 23 de julio de 1649, en BNM, Mss. 2380, y la relación remitida por el representante genovés en Madrid que subrayaba con estas palabras los ultrajes recibidos: «di questa azione inescusabile quanto inaudita è rimasta altamente offesa la mia repubblica nella delicta pupilla della sua reputazione.» Memorial de Pallavicini, Madrid, 30 de julio de 1649, Archivio di Stato di Genova (ASGe), Archivio Segreto, leg. 2447.

80. No en vano, el virrey de Nápoles, el influyente conde de Castrillo escribió a Caracena exigiéndoles mayores explicaciones en torno al procedimiento para aplicar el embargo, Carta de Castrillo a Caracena Nápoles a 2 de mayo de 1654, en Archivio di Stato di Napoli (ASN), Segreterie dei Vicerè, leg. 181. Véase también la pormenorizada Relación de bienes de genoveses confiscados, Nápoles, julio 1654, en AGS, Estado, leg. 3607.

Ediciones Universidad de Salamanca / 요 Stud. his., H. ${ }^{a}$ mod., 41, n. 1 (2019), pp. 189-230 
Guisa se saldaba con un completo desastre. En junio de 1654, el rey Cristinanísimo elevó una propuesta firme de alianza militar por la que se comprometía a asistir a la república con importantes efectivos hasta que Felipe IV no retirase el embargo y en la que proponía realizar un asiento de seis galeras además de actuar como mediador ante el Papa para que reconociese los honores regios a lo que aspiraba la Serenísima ${ }^{81}$. En enero del año siguiente, Hugues de Lionne realizó una parada en Génova camino de Roma y pronunció un entusiasta discurso ante las principales autoridades en el que acusaba a determinados particulares de hipotecar los intereses de la república en beneficio propio al estar ligados por una cadena de oro a las directrices de rey de España. Advertía asimismo con firmeza sobre «l'ambitione spagnola di rendersi affato tutta serva l'Italia» por lo que les animaba a aliarse con un rey enérgico como Luis XIV «con una fioritissima e robostissima gioventú con somma avversione all'ozio» y a romper los lazos de dependencia con Felipe IV «avanzato nell'etá senza speranza di figlioli maschi e dovendo per cio l'hereditá di suoi divisi stati trasmettersi per via di femine nelle convulsioni di quella corona a prencipe forestiero.» ${ }^{82}$

No le faltaba razón a Lionne cuando ponía el acento en los enraizados intereses que algunas de las principales familias de la república tenían en los dominios del rey Católico. Las amenazas de ampliar el embargo al reino de Castilla inclinaron de nuevo a Génova a la negociación. El envío a Madrid de Gio Francesco Sauli en calidad de embajador extraordinario no tardó en dar sus frutos y el conflicto se resolvió mediante la devolución de las naves apresadas y la suspensión del embargo ${ }^{83}$. Al año siguiente, la corona autorizaba la puesta en marcha de un convoy entre Génova y Cádiz, que estaría operativo hasta 1680, lo que permitía garantizar la protección de las partidas de plata entre ambas ciudades y rebajaba de forma sustancial las tensiones. Los perniciosos efectos de la epidemia de peste que se desató en la república a finales de 1656, y que ya había causado estragos en Nápoles, supusieron un fuerte golpe para la elite dirigente, que se vio sustancialmente mermada, y mitigó los proyectos autonomistas cuyos resultados habían sido decepcionantes y se habían traducido en un sustancial aumento de la presión fiscal. En estas circunstancias, los sectores que se inclinaban por recuperar las buenas relaciones con la Monarquía Hispánica volvieron a tomar la iniciativa. El avance militar francés en el Milanesado suscitó

81. Proposizione dei ministri del Cristianesimo alia repubblica di Genova per far lega offensiva e difensiva incluida en una carta enviada a la república por Louis Delomenie, Reims a 11 de junio de 1654, en BNM, Mss. 1443.

82. Discorso alla Serenissima repubblica di Genova fatto a nome del Ré Cristianissimo nel mese di genaio a 16 nell'anno 1655 da monsieur De Leone, ambasciadore destinato in Roma dalla medessima Maestá, en BNM, Mss 2384, fol. 313-315.

83. Consulta del Consejo de Estado en el que se aprueban las condiciones del acuerdo con Génova, Madrid, 12 de diciembre de 1654, en AGS, Estado, leg. 3607.

Ediciones Universidad de Salamanca / @®@@ Stud. his., H. ${ }^{a}$ mod., 41, n. 1 (2019), pp. 189-230 
MANUEL HERRERO SÁNCHEZ

LAS REPÚBLICAS MERCANTILES DE GÉNOVA Y LAS PROVINCIAS UNIDAS

ANTE EL CONFLICTO HISPANO-FRANCÉS POR LA HEGEMONÍA (1635-1659)

el temor ante las ambiciones del duque de Saboya sobre Génova lo que sumado a la activa campaña de los corsarios franceses en el Mediterráneo inclinó de nuevo al patriciado de la república en favor de la tradicional alianza española que, al menos, no resultaba amenazadora para la integridad territorial de la república. El acuerdo quedó sancionado con motivo de la firma de la paz de los Pirineos, cuando Génova se integró en la garantía del mismo en calidad de aliada del rey Católico ${ }^{84}$.

\section{LAS PROVINCIAS UNIDAS: DEL CONFLICTO MILITAR A LA ALIANZA EN DEFENSA DE LA ESTABILIDAD INTERNACIONAL}

La evolución de las relaciones entre la Monarquía Hispánica y las Provincias Unidas siguió un camino sustancialmente diferente al experimentado por Génova y constituye una prueba elocuente sobre la interdependencia que la corona tenía con respecto a este tipo de agregados urbanos de fuerte capacidad mercantil. Entre 1635 y 1659, conforme se debilitaron los lazos entre Madrid y Génova, la dinámica república neerlandesa pasó de actuar como uno de los más peligrosos enemigos para la seguridad del sistema imperial hispánico, en especial en el espacio ultramarino, a convertirse en su principal sostén y en el más firme aliado del monarca Católico ${ }^{85}$.

El largo conflicto militar desatado tras el estallido de la revuelta de Flandes había permitido a las Provincias Unidas dotarse de un notable grado de autonomía política que reposaba en su capacidad para interiorizar los costes de protección sin necesidad de depender, como le ocurría a Génova, de la ayuda militar de una potencia territorial. Es incuestionable que los cuantiosos subsidios y los recursos militares aportados por los enemigos de los Habsburgo habían actuado como un factor crucial para consolidar la independencia y para garantizar el necesario reconocimiento internacional de la joven república. Ahora bien, las Provincias Unidas dieron pruebas de su capacidad para garantizar su defensa gracias a la compleja combinación entre el componente territorial aportado por el Príncipe de Orange, que desde su cargo de Estatúder y capitán general de las principales provincias mantenía enlaces dinásticos con algunas de las grandes casas europeas como los Estuardo o los Hohenzollern, con el componente capitalista procedente de los inagotables recursos de los que disponía el rico patriciado de las poderosas ciudades holandesas, en especial de

84. Consulta del Consejo de Estado sobre la solicitud del residente genovés en Madrid para que, en el marco del artículo 122 del tratado de los Pirineos, el rey Católico declarase a la república de Génova como su aliada, Madrid, 8 de abril de 1660, en AGS, Estado, leg. 3609.

85. Un pormenorizado análisis sobre este proceso de cambio de alianzas en HERRERO SÁNCHEZ, El acercamiento..., op. cit. así como, del mismo autor, HERRERO SÁNCHEZ, M.: «Continuity and Change in Spanish-Dutch Relations between Westphalia (1648) and Utrecht (1714)», en SCHMIDT-VOGES, I. y CRESPO SOLANA, A. (eds.): New Worlds? Transformations in the Culture of International Relations. Londres y Nueva York, 2017, pp. 58-78.

Ediciones Universidad de Salamanca / @®@@ Stud. his., H. ${ }^{a}$ mod., 41, n. 1 (2019), pp. 189-230 
Ámsterdam, que actuaba desde finales del siglo XVI como el principal emporio mercantil y el más dinámico centro financiero de Europa ${ }^{86}$.

Esta compleja suma de esfuerzos entrañaba, sin embargo, una serie de tensiones derivadas del elevado grado de fragmentación de la soberanía que se vio agudizado por las considerables concesiones otorgadas a las dos compañías de comercio privilegiado creadas a principios del siglo XVII para desafiar a la Monarquía Hispánica tanto en Asia, la VOC, como en el espacio atlántico, la WIC. Ambas compañías gozaban de plena autonomía para operar en el espacio ultramarino por lo que su aquiescencia era fundamental para que la república pudiera alcanzar acuerdos diplomáticos que afectaban a los espacios bajo sus respectivas jurisdicciones ${ }^{87}$. En estas circunstancias, la posibilidad de que su antiguo soberano reconociese la independencia de las Provincias Unidas y pusiese fin a los perjudiciales efectos que la política de embargos comerciales tenía sobre los intercambios mercantiles de la república, no sólo tenía que vencer las reticencias de las compañías de comercio sino que debía hacer frente también a la férrea oposición del Príncipe de Orange. El ascendiente del Estatúder emanaba del permanente estado de guerra y contaba con el sustento de los principales centros textiles que, como Leiden, veían con recelo la competencia de la producción flamenca, y de los grupos calvinistas más intransigentes, que instigaban las tensiones sociales que enfrentaban a los sectores populares con la elite de los regentes a la que acusaban de poner sus meros intereses personales por encima de los de la república y de adoptar una postura tibia en cuestiones religiosas ${ }^{88}$.

En un principio, la ruptura de hostilidades entre Francia y la Monarquía Hispánica en 1635 dio alas a los sectores belicistas y se concretó en la firma del tratado de París por el que se acordaba el reparto de los Países Bajos españoles entre ambos aliados y se articulaba un plan de ataque en varios frentes que no tardó en dar excelentes resultados. La destrucción de la flota de guerra española en la batalla de las Dunas en 1639 y las conquistas territoriales neerlandesas tanto en Brasil como en Asia vinieron a sumarse al paulatino avance de los efectivos franceses en la frontera meridional de Flandes ${ }^{89}$. Ahora bien, el estallido de la revuelta catalana y la restauración de la independencia del reino de Portugal al año siguiente provocaron un vuelco en la

86. GELDERBLOM, O.: Cities of Commerce. The Institutional Foundation of International Trade in the Low Countries, 1250-1650. Princeton y Oxford, 2013. Sobre los fuertes vínculos y concomitancias con las ciudades flamencas y brabanzonas bajo la jurisdicción del monarca católico, en especial con Amberes, véase LINDEMANN, M.: The Merchant Republics. Amsterdam, Antwerp and Hamburg, 1648-1790. Cambridge, 2015.

87. ADAMS, J.: The Familial State: Ruling Families and Merchant Capitalism in Early Modern Europe. Nueva York, Ithaca, 2005. 1998.

88. ISRAEL, J. I.: The Dutch Republic: Its Rise, Greatness, and Fall 1477-1806. Oxford,

89. ALCALÁ-ZAMORA, J.: España, Flandes y el Mar del Norte (1618-1639). La última ofensiva europea de los Austrias madrileños, Madrid, 2001 (1ª edición, 1975).

Ediciones Universidad de Salamanca / అ@@ Stud. his., H. ${ }^{a}$ mod., 41, n. 1 (2019), pp. 189-230 
situación y abrieron el camino al entendimiento con Madrid. Con la excepción de la isla de Curaçao y de otros pequeños enclaves en el Caribe, la expansión ultramarina de la república se había hecho a costa de los dominios lusos, lo que venía a eliminar uno de los principales escollos para el acuerdo. El avance de las armas francesas en Artois y en Hainaut y la derrota de los tercios en la batalla de Rocroi en 1643, aunque estuvieron lejos de laminar la capacidad de acción de los efectivos militares españoles en la zona, evidenciaron los peligros que podría entrañar la vecindad de Francia para la seguridad de la república. Este cambio de escenario facilitó el inicio de las conversaciones de paz en Westfalia que, tras la llegada en 1645 del conde de Peñaranda a Münster, experimentaron un notable impulso lo que allanó el camino para un acuerdo bilateral. Su estrategia se centró, en sus propias palabras, en «ir aumentando los celos en que ya han entrado franceses y holandeses» por lo que no titubeó a la hora de airear las tratativas que mantenía con Francia destinadas a canjear los Países Bajos por otro territorio en calidad de dote por un posible matrimonio entre Luis XIV y la infanta María Teresa ${ }^{90}$. Para principios de 1646, las delegaciones española y neerlandesa parecían haber alcanzado un borrador de acuerdo que se vio estimulado tras la caída en manos francesas del estratégico puerto de Dunkerque, en octubre de ese mismo año, y el fallecimiento, poco días después, del príncipe Baltasar Carlos. A pesar de algunos obstáculos, interpuestos por las provincias de Zelanda y de Utrecht o por el príncipe de Orange, las negociaciones culminaron el 30 de enero de 1648 con la firma de una paz al margen de sus respectivos aliados franceses e imperiales por la que el monarca Católico reconocía la plena soberanía de sus antiguos súbditos.

Las expectativas generadas por dicho acuerdo no tardaron en concretarse y actuaron como una barrera eficaz para frenar los intentos de aquellos sectores que apostaban por una nueva ruptura de hostilidades. La prematura muerte del nuevo Estatúder, Guillermo II, antes incluso del nacimiento de su heredero, dejó el camino libre al partido de los regentes que, de la mano de los hermanos De Witt, impuso hasta la invasión franco-británica de 1672 el denominado programa de la «verdadera libertad». Mediante una sustancial reducción de los efectivos militares y una completa marginación del príncipe de Orange de los asuntos de gobierno, que culminó con el Acta de Exclusión de 1654, la república se inclinaba por una política de neutralidad en los conflictos territoriales que afectaban a Europa y concentraba sus energías en la promoción de la marina y de los intereses mercantiles. En este contexto, los sucesivos intentos de la Monarquía Hispánica por arrancar un tratado de alianza en contra de Francia no dieron los frutos deseados. No obstante, la corona pudo contar a partir de entonces con el sostén naval y financiero de las Provincias Unidas lo que le permitió compensar, en gran medida, la mala coyuntura que vivían

90. Carta del conde de Peñaranda a Ronquillo, Munster, 13 de octubre de 1645, en BNM, Mss. 2377.

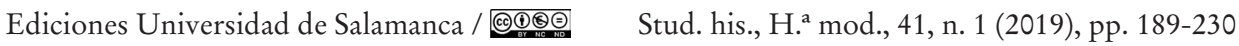


sus relaciones con su antiguo aliado genovés y facilitaron el avance de los efectivos militares españoles en todos los frentes durante la primera década de 1650.

Como contraprestación, el monarca católico no sólo reconoció por vez primera la ruptura de su teórico monopolio en las Indias sino que permitió también el mantenimiento del cierre del Escalda y la aplicación de una serie de barreras aduaneras perjudiciales para los intereses de sus súbditos flamencos, mientras que facilitaba la acción de los hombres de negocios de la república en sus dominios ${ }^{91}$. Junto al establecimiento de una abigarrada red de consulados en los principales puertos de la Monarquía Hispánica, el tratado de comercio y Navegación acordado el 17 de diciembre de 1650 ponía trabas a la acción de los veedores de contrabando y limitaba de forma sustancial los controles sobre las naves neerlandesas que obtenían, de este modo, una notable ventaja comparativa frente al resto de los entramados transnacionales que operaba en los mercados españoles ${ }^{92}$. Como ha señalado Jonathan Israel, tan beneficiosas concesiones actuaron como una palanca para dotar de renovadas fuerzas al emporio neerlandés y estuvieron en el origen del primer enfrentamiento naval con Inglaterra cuyos mercaderes, a pesar de las buenas relaciones que Felipe IV mantenía con la Commonwealth, se vieron desplazados con facilidad por tan activos competidores $^{93}$. Aunque la Monarquía Hispánica mantuvo una rigurosa neutralidad en el conflicto naval que se desató entre ambas repúblicas entre 1652 y 1654, una vez concluida la contienda, Cromwell se decantó por romper hostilidades con el monarca Católico mediante el envío de una poderosa flota al Caribe en 1655 que, a pesar de sus mediocres resultados, logró ocupar la isla de Jamaica. Más perjudiciales resultaron los ataques sistemáticos contra el sistema de Flotas y Galeones que sufrieron importantes disrupciones entre 1656 y 1657, lo que interrumpió el flujo de numerario y provocó graves problemas para la obtención de nuevos préstamos en un momento en el que los efectivos militares del rey tenían frentes abiertos en Flandes, Milán y Portugal. Las constantes interferencias en la llegada de las remesas americanas, fundamentales para imponerse en los mercados asiáticos y en el Levante otomano, afectaron de manera dramática a algunos de los principales vértices del emporio mercantil neerlandés por lo que determinados grupos de presión, en contra

91. En 1649, Felipe IV concedía al marqués de Velada el título de «protector de los vasallos de las Provincias Unidas en todos sus reinos», Carta del cónsul en Cádiz Jacob Van den Hove a los Estados Generales informando de dicho nombramiento, Cádiz a 1 de agosto de 1649, en ARH, Staten-Generaal, leg. 7042.

92. ECHEVARRÍA BACIGALUPE, M. A.: «Las relaciones económicas hispanoholandesas y los tratados de 1648 al 1650», en LECHNER, J. (ed.): España y Holanda. Ponencias leídas en el quinto coloquio hispano-bolandés de historiadores. Amsterdam, 1995, pp. 27-43.

93. ISRAEL, J. I.: «England's Mercantilist Response to Dutch World Trade Primacy, 1647-1674», en Conflicts of Empires. Spain, the Low Countries and the Struggle for World Supremacy, 1585-1713. Londres, 1997, pp. 305-318.; ISRAEL, J. I.: Dutch Primacy in World Trade, 1585-1740. Oxford, 1989. 
de la teórica neutralidad del gobierno, forzaron el envío de poderosos efectivos navales para colaborar en la protección de la Carrera de Indias ${ }^{94}$. Algo semejante a lo que, desde la isla de Curaçao, habían hecho bajo cuerda determinados particulares neerlandeses que se beneficiaban de la permisividad de las autoridades españolas locales para maniobrar en el Caribe, mediante el envío de provisiones y bastimentos destinados a frustrar el intento inglés de apoderarse de Santo Domingo. A pesar de los esfuerzos del Consejo de Indias por poner coto a cualquier tipo de colaboración oficial con la república en el ámbito ultramarino, el papel de los entramados sefarditas para impulsar una mayor colaboración no hizo sino crecer y se convirtió en una de las principales razones para impulsar la vuelta al sistema de los asientos con determinados particulares para proveer las Indias de mano de obra esclava. La concesión del asiento de negros a la firma genovesa de Grillo y Lomelín en 1662 y el permiso explícito para que los agentes de los asentistas pudieran proveerse de los esclavos en los dominios de la WIC dio alas al contrabando y fortaleció los mutuos intereses hispano-neerlandeses en América.

En el Mediterráneo occidental, la activa campaña que los corsarios al servicio del rey de Francia llevaron a cabo a partir de mediados de la década de 1650 al objeto de interrumpir las comunicaciones navales entre los dominios ibéricos e italianos de la corona y que, como hemos señalado, había sido uno de los motivos que había vuelto a inclinar a Génova del lado español, afectó de manera dramática la notable expansión experimentada tras la firma de la paz de Münster por los intercambios neerlandesas en la zona. La escalada de tensión entre Francia y las Provincias, que coincidió con un fuerte choque protocolario entre los embajadores francés y español en las calles de La Haya ${ }^{95}$, culminó con el envío de una escuadra holandesa al mando de Ruyter que contó con el necesario sostén logístico del rey Católico para actuar en sus puertos y para poder vender en los dominios del rey las naves y las mercancías apresadas ${ }^{96}$. Estas tensiones coincidían con los problemas que experimentaron los comerciantes neerlandeses en el Báltico, un espacio que constituía una de las

94. Son innumerables los testimonios al respecto. Véase, a modo de ejemplo Carta del gobernador de los Países Bajos, Don Juan de Austria, al rey sobre las negociaciones de Gamarra con el burgomaestre de Ámsterdam para que el almirante Ruyter pudiera cooperar en la defensa de la Flota que debia llegar a Cádiz, Bruselas, 2 de diciembre de 1656, en AGRB, SEG, 261, f. 287.

95. En el que, según le indicaba Esteban de Gamarra a Luis de Haro, la población se había puesto de su lado, a su modo de ver, por su conocimiento del flamenco por lo que señalaba: «...este caso me obliga a decir a Vuestra Excelencia que si viniese a faltar o que Su Majestad me mandase salir de este empleo, convendrá sumamente a su Real Servicio que mi sucesor sepa hablar flamenco que les gana mucho la afición de oír su lengua; y decían los burgueses a este le hablamos y entendemos pero al otro no sabemos lo que está gruñendo entre dientes.» Carta de Gamarra a Luis de Haro, La Haya, 16 de agosto de 1657, en AGS, EEH, leg. 8471 (1), f. 125-128.

96. Consulta de la Junta de Estado de Bruselas sobre los motivos de enfrentamiento entre franceses y holandeses en el Mediterráneo, Madrid a 19 de mayo de 1657, en AGS, Estado, leg. 2091.

Ediciones Universidad de Salamanca / 요 Stud. his., H. ${ }^{a}$ mod., 41, n. 1 (2019), pp. 189-230 
piezas maestras para un adecuado funcionamiento de su emporio mercantil a la hora de asegurar el abastecimiento de trigo, madera y pertrechos navales. El apoyo franco-británico al rey de Suecia en el conflicto que mantenía por el control del Sund con Dinamarca, el aliado preferente de La Haya, provocó un aumento de la tensión que venía a sumarse a la ruptura de hostilidades de la república contra otro de los principales enemigos del rey Católico, el reino rebelde de Portugal.

Tras la recuperación de Brasil por parte de los Braganza en 1654, y en plena ofensiva de la VOC para desplazar a los portugueses de algunos de sus principales enclaves en la India y en Ceilán, las presiones de la WIC forzaron en 1657 el bloqueo del puerto de Lisboa lo que facilitó las sucesivas ofensivas de la Monarquía Hispánica en la frontera lusa. Los esfuerzos de Madrid para alcanzar una alianza efectiva con la república contra un enemigo común que contaba con el apoyo militar francobritánico no dieron los frutos deseados. A pesar de que a lo largo del año 1658 el representante de los Estados Generales en Madrid entabló negociaciones directas con el marqués de los Balbases, el genovés Filippo Spinola, que se hizo cargo de las tratativas por la ausencia de Haro, los intentos por garantizar el apoyo naval de las Provincias Unidas a cambio de un acceso directo a la salinas de Araya en la costa de Venezuela, no fructificaron ${ }^{97}$. El avance de las negociaciones de paz entre el monarca Católico y Francia en los Pirineos, tras la nueva caída de Dunkerque ese mismo año, y el compromiso alcanzado entre el rey Cristianísimo, Inglaterra y las Provincias Unidas para mediar en el conflicto del norte, que garantizaba la libre circulación en el Báltico, se sumaron a la escasa capacidad decisoria del delegado de la república y dieron al traste con este nuevo intento por abrir una nueva fisura en el pretendido monopolio de la corona sobre las Indias.

\section{CONSIDERACIONES FINALES}

La firma de la paz de los Pirineos y de los sucesivos acuerdos diplomáticos en el norte de Europa abrieron un periodo de inusitada tranquilidad. En principio, dicho escenario parecía responder a los deseos de estabilidad del partido de los regentes que controlaba el gobierno de las Provincias Unidas y que, al igual que la república de Génova, observaba con agrado una paz que nos le forzaba a tener que decantarse del lado de ninguna de las dos grandes potencias territoriales. Sin embargo, esta aparente quietud entrañaba una serie de amenazas que no tardaron en

97. Relación del marqués de los Balabases ante el Consejo de Estado sobre su primera reunión con el residente De Reede, Madrid, 31 de Agosto de 1658, en AGS, Estado, leg. 2092 (2). En noviembre se llegó a elaborar un borrador con los principales punto de un acuerdo que finalmente no prosperó, Borrador del acuerdo alcanzado entre el Marqués de los Balbases y Enrique de Reede, Madrid, 8 de noviembre de 1658, en AGS, Estado, leg. 2092 (2).

Ediciones Universidad de Salamanca / అ@@ Stud. his., H. ${ }^{a}$ mod., 41, n. 1 (2019), pp. 189-230 
desencadenarse y que afectaron de manera harto negativa a los intereses comerciales de ambas repúblicas. Las numerosas concesiones que Madrid se vio obligada a ofrecer a los hombres de negocios franceses superaron incluso a las ya abusivas condiciones de las que disfrutaban los neerlandeses, como acreditaba el hecho de que los jueces conservadores encargados de dirimir los pleitos que afectaban a los comerciantes franceses pudiese entender también de cuestiones relacionadas con la jurisdicción criminal. Además, a partir de entonces, y de manera especial tras el nombramiento de Jean-Baptiste Colbert como intendente de Finanzas, el rey Cristianísimo se embarcó en una espiral de sanciones destinadas a romper la dependencia que la monarquía tenía con respecto a los intermediarios comerciales de las Provincias Unidas. La guerra de tarifas culminó en 1667 con una rigurosa lista de aranceles que corría en paralelo con el impacto negativo que para el emporio neerlandés se había derivado del estallido del segundo conflicto naval con Inglaterra desde 1664.

El enfrentamiento económico vino a sumarse a un rápido agravamiento de las relaciones políticas franco-neerlandesas. La muerte de Felipe IV en 1665 abrió paso a la espinosa cuestión de la sucesión y puso de manifiesto las pretensiones territoriales de Luis XIV sobre los Países Bajos. Durante la guerra de Devolución, la Monarquía Hispánica supo jugar con habilidad con los peligros de su ausencia y logró involucrar por vez primera al resto de las potencias europeas en el mantenimiento del equilibrio de poderes en el continente. El liderazgo mostrado por las Provincias Unidas en la conformación de la Triple Alianza, que condujo en 1668 a la firma de la paz de Aquisgrán, aceleró los deseos de Francia de desprenderse de la tutela de las repúblicas mercantiles por la vía militar y culminó con la invasión de las Provincias Unidas en 1672 y con el posterior bombardeo de la república de Génova en 1684. Se trataba, a fin de cuentas, de exteriorizar la plena soberanía que el monarca francés tenía sobre su territorio por lo que este tipo de acciones militares vinieron acompañadas de una formidable campaña propagandística, como acreditan la erección de los arcos de Saint Denis y Saint Martin en París, el programa iconográfico del salón de los espejos o la humillación a la que fue sometido el dux de Génova que, en contra de las leyes de la república, fue obligado a desplazarse hasta Francia para inclinarse a los pies de Luis XIV en Versalles.'

Se trataba de un camino del todo diferente al seguido por el rey Católico que aprovechó la beligerancia de Francia para entablar una firme alianza con las Provincias Unidas en la que logró involucrar tanto al Emperador como, con posterioridad, a Inglaterra. La firma del tratado de La Haya en 1673, aunque no fue suficiente para frenar el avance francés en los Países Bajos, permitió a los Habsburgo presentarse a los ojos de Europa como los principales garantes de la supervivencia de este tipo de estructuras políticas policéntricas de marcado carácter urbano cuya autonomía se veía cuestionada por el nuevo modelo de soberanía plena postulado por Francia. 
MANUEL HERRERO SÁNCHEZ

LAS REPÚBLICAS MERCANTILES DE GÉNOVA Y LAS PROVINCIAS UNIDAS

ANTE EL CONFLICTO HISPANO-FRANCÉS POR LA HEGEMONÍA (1635-1659)

\section{BIBLIOGRAFÍA}

ADAMS, J.: The Familial State: Ruling Families and Merchant Capitalism in Early Modern Europe. Nueva York, Ithaca, 2005.

ALCALÁ-ZAMORA, J.: España, Flandes y el Mar del Norte (1618-1639). La última ofensiva europea de los Austrias madrileños. Madrid, Centro de Estudios Políticos y Constitucionales, 2001 (1ª edición, 1975).

ALBAREDA SALVADÓ, J.: La Guerra de Sucesión española (1700-1714). Barcelona, Crítica, 2010.

ALLOZA, A.: «La Monarquía Católica y la Commonwealth of England», en HERRERO SÁNCHEZ, M. (ed.): Republicas y republicanismo en la Europa Moderna (siglos XVIXVIII). Madrid, Fondo de Cultura Económica, 2017, pp. 349-370.

BEN YESSEF GARFIA, Y. R.: «Una transnacionalitat eminentment mediterrània. Diversificació i estratègies en l'entramat familiar genovès dels Serra durant les primeres dècades del segle XVII», Afers: fulls de recerca i pensament, 32, 87, 2017, pp. 391-414.

BEN YESSEF GARFIA, Y. R.: «Una familia genovesa entre la República y la Monarquía Hispánica: Batista Serra como modelo de la red en un sistema policéntrico entre finales del siglo XVI y la década de 1620», en HERRERO SÁNCHEZ, M. (ed.): Repúblicas y republicanismo en la Europa Moderna (siglos XVI-XVIII). Madrid, Fondo de Cultura Económica, 2017, pp. 229-248.

BEN YESSEF GARFIA, Y. R.: «Bautista Serra, un agente genovés en la Corte de Felipe III», Hispania, LXXIII, 2013, pp. 647-672.

BENIGNO, F.: «Una repubblica monarchica ? Riflessioni su teorie politiche e pratiche di governo nella Spagna del Seicento", en PARDOS, J. et al (eds.): Historia en fragmentos. Estudios en homenaje a Pablo Fernández Albaladejo, Madrid, UAM, 2017, pp. 387-396.

BENIGNO, F.: Las palabras del tiempo. Un ideario para pensar históricamente. Madrid, Cátedra, 2013.

BEHR, A.: «La representación de los Cantones suizos en la corte de España a finales del siglo XVII: un primer acercamiento", Dimensioni e problemi della ricerca storica, 1 , 2014, pp. 167-189.

BIRAGO AVOGADRO, G.: Turbolenze di Europa dall'anno 1640 fino al 1650. Venecia, li Ginammi, 1654.

BITOSSI, C.: «Il Genio ligure risvegliato. La potenza navale nel discorso politico genovese del Seicento», en CANTÙ, F. (ed.): Linguaggi del potere nell'età barocca. Roma, Viella, 2009, pp. 81-112.

BITOSSI, C.: Il governo dei magnifici. Patriziato e politica a Genova fra Cinque e Seicento. Génova, Ecig, 1990.

BOTERO, G.: Dalla ragion di stato, a cura di L. Firpo, Turín, UTET, 1948 [Primera versión 1598].

BRAUN, G.: Du roi Soleil aux Lumières. Histoire Franco-allemande. Lille, Septentrion, 2012.

BRAVO LOZANO, C.: «¿Antemural de la fe o tierras de misión?: Reflexiones en torno al Norte y la proyección confesional de la monarquía de España, 1665-1700», en GARCÍA MARTÍN, P., QUIRÓS ROSADO, R. y BRAVO LOZANO, C. (coords.):

Ediciones Universidad de Salamanca / అ@@ Stud. his., H. ${ }^{a}$ mod., 41, n. 1 (2019), pp. 189-230 
MANUEL HERRERO SÁNCHEZ

LAS REPÚBLICAS MERCANTILES DE GÉNOVA Y LAS PROVINCIAS UNIDAS

ANTE EL CONFLICTO HISPANO-FRANCÉS POR LA HEGEMONÍA (1635-1659)

Antemurales de la Fe: conflictividad confesional en la Monarquía de los Habsburgo, 1516-1714. Madrid, UAM, 2015, pp. 213-240.

CARDIM, P.: «La jurisdicción real y su afirmación en la Corona portuguesa y sus territorios ultramarinos (siglos XVI-XVIII). Reflexiones sobre la historiografía», en F. J. ARANDA PÉREZ y DAMIÀO RODRIGUES, J. (eds.): De Re Publica Hispaniae. Una vindicación de la cultura política en los reinos ibéricos en la primera modernidad. Madrid, Sílex, 2008, pp. 349-388.

CARDIM, P., HERZOG, T., RUIZ IBÁÑEZ, J. J. y SABATINI, G. (eds.): Polycentric Monarchies. How Did Early Modern Spain and Portugal Achieve and Maintain A Global Hegemony? Eastbourne, Sussex Academic Press, 2012.

CARPENTIER, B. y PRIOTTI J.-P.: «La forge instable d'une domination. Les Doria, Gênes et la Monarchie Hispanique (1560-1606)», en PRIOTTI J.-P. (ed.): Identités et territoires dans les mondes hispaniques (XVIe-XXe siècle). Rennes, PUR, 2015, pp. 75-96.

CARRIÓ-INVERNIZZI, D. (dir.): Embajadores culturales: transferencias y lealtades de la diplomacia española de la Edad Moderna. Madrid, UNED, 2016.

CHANET, J.-F. y WINDLER, C. (eds.).: Les resources des faibles. Neutralités, sauvegardes, accommodements en temps de guerre (XVIe-XVIIe siécles). Rennes, PUR, 2009.

CHITTOLINI, G., MOLHO, A. y SCHIERA, P. (eds.): Origini dello Stato. Processi di formazione statale in Italia fra medioevo ed età moderna. Bolonia, Il Mulino, 1994.

CIASCA, R.: Istruzioni e relazioni degli Ambasciatori genovesi. Roma, Istituto Storico Italiano per l'età moderna e contemporánea, 1951-1968.

CIASCA, R.: «Affermarsi di sovranità della repubblica di Genova nel secolo XVII», Giornale storico e letterario della Liguria, XIV, 1938, pp. 169-170.

COLLINS, J. B.: La monarchie républicaine. État et société dans la France moderne. París, Odile Jacob, 2016.

COSTANTINI, C.: «Política e storiografia: l'epoca dei grandi repubblichisti», en La letteratura ligure. La Repubblica aristocrática (1528-1797). Génova/Trento, Costa \& Nolan, 1992, Vol. Il, pp. 93-135.

DUBET, A. y RUIZ IBÁÑEZ, J. J. (eds): Las monarquías española y francesa (siglos XVIXVIII). ¿Dos modelos políticos? Madrid, Casa de Velázquez, 2010.

EBBEN, M.: Un holandés en la España de Felipe IV. Diario de viaje de Lodewijck Huygens, 1660-1661. Madrid, Doce Calles, 2010.

ECHEVARRÍA BACIGALUPE, M. A.: «Las relaciones económicas hispano-holandesas y los tratados de 1648 al 1650», en LECHNER, J. (ed.): España y Holanda. Ponencias leidas en el quinto coloquio hispano-bolandés de historiadores. Ámsterdam, Rodopi, 1995, pp. 27-43.

FELLONI, G.: Gli investimenti firianziari genovesi in Europa tra il Seicento e la Restaurazione. Milán, Giuffè editore, 1971.

FRIGO, D.: «Politica e diplomazia. I sentieri della storiografia italiana», en SABBATINI, R. y VOLPINI, P. (eds.): Sulla diplomazia in età Moderna. Politica, economica, religione. Milán, Franco Angeli, 2011, pp. 35-59.

Ediciones Universidad de Salamanca / అ@@ Stud. his., H. ${ }^{a}$ mod., 41, n. 1 (2019), pp. 189-230 
MANUEL HERRERO SÁNCHEZ

LAS REPÚBLICAS MERCANTILES DE GÉNOVA Y LAS PROVINCIAS UNIDAS

ANTE EL CONFLICTO HISPANO-FRANCÉS POR LA HEGEMONÍA (1635-1659)

FRIGO, D.: «Politica estera e diplomazia: figure, problema e apparati», en GRECO, G. y ROSA, M. (eds.): Storia degli antichi stati italiani. Roma, Editori Laterza, 1997, pp. 117-161.

GARCÍA MONTÓN, A.: «Trayectorias individuales durante la quiebra del sistema hispano-genovés: Domingo Grillo (1617-1687)», en HERRERO SÁNCHEZ, M., BEN YESSEF, Y. R., BITOSSI, C. y D. PUNCUH (eds.): Génova y la Monarquía Hispánica, 1528-1713. Génova, Atti della Società Ligure de Storia Patria, 2011, pp. 367-384.

GELDERBLOM, O.: Cities of Commerce. The Institutional Foundation of International Trade in the Low Countries, 1250-1650. Princeton y Oxford, Princeton University Press, 2013.

GREVER, J.H.:: «The Structure of Decision-Making in the States General of the Dutch Republic 1660-1668", Parliaments, Estates and Representation, 2, 1982, pp. 125-152.

HERRERO SÁNCHEZ, M.: «La memoria de la revuelta de Flandes en la toma de decisiones y en la acción política de la Monarquía Hispánica entre 1621 y 1700», en MERLE, A., JETTOT, S. y HERRERO SANCHEZ, M. (eds.): La Mémoire des révoltes en Europe à l'époque moderne, París, Classiques Garnier, 2018, pp. 309-331.

HERRERO SÁNCHEZ, M.: «Urban Republicanism and Political Representation in the Spanish Monarchy", en ALBAREDA, J. y HERRERO SÁNCHEZ, M. (eds.): Political Representation in the Ancien Régime. Londres/New York, Routledge, 2018, pp. 319-332.

HERRERO SÁNCHEZ, M. (ed.): Repúblicas y republicanismo en la Europa Moderna (siglos XVI-XVIII). Madrid, Fondo de Cultura Económica, 2017.

HERRERO SÁNCHEZ, M.: «La Monarquía Hispánica y las repúblicas europeas. El modelo republicano en una monarquía de ciudades», en HERRERO SÁNCHEZ, M. (ed.): Repúblicas y republicanismo en la Europa Moderna (siglos XVI-XVIII). Madrid, Fondo de Cultura Económica, 2017, pp. 273-328.

HERRERO SÁNCHEZ, M.: "Continuity and Change in Spanish-Dutch Relations between Westphalia (1648) and Utrecht (1714)», en SCHMIDT-VOGES, I. y CRESPO SOLANA, A. (eds.): New Worlds? Transformations in the Culture of International Relations, Londres y Nueva York, Routledge, 2017, pp. 58-78.

HERRERO SÁNCHEZ, M.: «Conectores sefarditas en una Monarquía policéntrica. El caso Belmonte/Schonenberg en la articulación de las relaciones hispano-neerlandesas durante la segunda mitad del siglo XVII», Hispania, LXXVI, 253, 2016, pp. 445-472.

HERRERO SÁNCHEZ, M.: «Paz, razón de estado y diplomacia en la Europa de Westfalia. Los límites del triunfo del sistema de soberanía plena y la persistencia de los modelos policéntricos (1648-1713)», Estudis. Revista de Historia Moderna, 41, 2015, pp. 43-65.

HERRERO SÁNCHEZ, M.: «La red diplomática de las Provincias Unidas en la Corte española durante la segunda mitad del siglo XVII», Dimensioni e problemi della ricerca storica, 1, 2014, pp. 131-163.

HERRERO SÁNCHEZ, M.: «La red genovesa Spínola y el entramado transnacional de los marqueses de los Balbases al servicio de la Monarquía Hispánica», en YUN

Ediciones Universidad de Salamanca / 요 Stud. his., H. ${ }^{a}$ mod., 41, n. 1 (2019), pp. 189-230 
MANUEL HERRERO SÁNCHEZ

LAS REPÚBLICAS MERCANTILES DE GÉNOVA Y LAS PROVINCIAS UNIDAS

ANTE EL CONFLICTO HISPANO-FRANCÉS POR LA HEGEMONÍA (1635-1659)

CASALILLA, B. (ed.): Las redes del Imperio. Élites sociales en la articulación de la Monarquía Hispánica, 1492-1714. Madrid, Marcial Pons, 2009, pp. 97-133.

HERRERO SÁNCHEZ, M.: «La quiebra del sistema hispano-genovés (1627-1700)», Hispania, LXV, 219, 2005, pp. 115-152.

HERRERO SÁNCHEZ, M.: «Génova y el sistema imperial hispánico», en ÁLVAREZOSSORIO, A. y GARCÍA, B. (eds.): La Monarquía de las naciones. Patria, Nación y Naturaleza en la Monarquía de España. Madrid, Fundación Carlos de Amberes, 2004, pp. 528-562.

HERRERO SÁNCHEZ, M.: El acercamiento hispano-neerlandés (1648-1678). Madrid, CSIC, 2000.

HERRERO SÁNCHEZ, M.: «Republican Diplomacy and the power balance in Europe», en ALIMENTO, A. (ed.): War, trade and neutrality. Europe and the Mediterranean in seventeenth and eighteenth centuries. Milán, Franco Angeli, 2011, pp. 23-40.

HERRERO SÁNCHEZ, M.: «La Monarquía Hispánica y el Tratado de La Haya de 1673», en LECHNER, J. y BOER, H. DER (eds.): España y Holanda. Ponencias leidas durante el quinto coloquio hispanobolandés de historiadores, Diálogos Hispánicos, n¹6, Amsterdam, 1995, pp. 103-118.

HERRERO SÁNCHEZ, M., BEN YESSEF, Y. R., BITOSSI, C. y PUNCUH, D. (eds.): Génova y la Monarquía Hispánica, 1528-1713. Génova, Atti della Società Ligure de Storia Patria, 2011, 2 Vols.

ISRAEL, J. I.: The Dutch Republic: Its Rise, Greatness, and Fall 1477-1806. Oxford, Clarendon Press, 1998.

ISRAEL, J. I.: «Spain and Europe from the Peace of Münster to the Peace of the Pyrénnées, 1648-1659", en ISRAEL, J. I.: Conflicts of Empires. Spain, the Low Countries and the Struggle for the World Supremacy, 1585 1713. Londres, Hambledon Press, 1997, pp. 105-144.

ISRAEL, J. I.: «Lopo Ramirez (David Curiel) and the Attempt to Establish a Sephardi Community in Antwerp in 1653-4», en ISRAEL, J. I.: Empires and Entrepots. The Dutch, The Spanish Monarchy and the Jews, 1585 1713. Londres, Hambledon Press, 1990, pp. 197-217.

ISRAEL, J. I.: «England's Mercantilist Response to Dutch World Trade Primacy, 1647-1674», en ISRAEL, J. I.: Conflicts of Empires. Spain, the Low Countries and the Struggle for World Supremacy, 1585-1713. Londres, Hambledon Press, 1997, pp. 305-318.

ISRAEL, J. I.: Dutch Primacy in World Trade, 1585-1740. Oxford, Clarendon Press, 1989.

JOUANNA, A.: Le pouvoir absolu, Naissance de l'imaginaire politique de la royauté. París, Gallimard, 2013.

JOVER ZAMORA, J. M. y LÓPEZ-CORDÓN CORTEZO, M. V.: «La imagen de Europa y el pensamiento político internacional», en El siglo del Quijote, 1580-1680, tomo XXVI-l de la Historia de España fundada por R. Menéndez Pidal. Madrid, Espasa Calpe, pp. 353-522.

KEBLUSEK, M. y VERA NOLDUS, B.: Double Agents. Cultural and Political Brokerage in Early Modem Europe. Leiden-Boston, Brill, 2011.

Ediciones Universidad de Salamanca / @®@@ Stud. his., H. ${ }^{a}$ mod., 41, n. 1 (2019), pp. 189-230 
MANUEL HERRERO SÁNCHEZ

LAS REPÚBLICAS MERCANTILES DE GÉNOVA Y LAS PROVINCIAS UNIDAS

ANTE EL CONFLICTO HISPANO-FRANCÉS POR LA HEGEMONÍA (1635-1659)

KIRK, T.: Genoa and the Sea: Policy and Power in an Early Modern Maritime Republic, 1559-1684. Baltimore, The Johns Hopkins University Press, 2013.

LAZZARINI, I.: «Storia della diplomazia e International Relations Studies fra pre-e postmoderno", Storica, 65, XXII, 2016, pp. 9-41.

LEFÈVRE, J. y P.: Inventaire des Archives de l'Ambassade d'Espagne à La Haye. Tongres, 1932.

LEVILLAIN, C.-E.: Le Procès de Louis XIV: Une guerre psychologique. París, Tallandier, 2015.

LEVILLAIN, C.-E.: Vaincre Louis XIV. Angleterre-Hollande-France. Histoire d'une relation triangulaire, 1665-1688. París, Champ Vallon, 2010.

LINDEMANN, M.: The Merchant Republics. Amsterdam, Antwerp and Hamburg, 1648-1790. Cambridge, Cambridge University Press, 2015.

LO BASSO, L.: «De Curaçao a Esmirna. El armamento marítimo en las estrategias económicas de los genoveses durante la segunda mitad del siglo XVII», en HERRERO SÁNCHEZ, M. (ed.): Repúblicas y republicanismo en la Europa Moderna (siglos XVI-XVIII). Madrid, Fondo de Cultura Económica, 2017, pp. 529-553.

MAISSEN, T.: «Inventing the Sovereign Republic. Imperial Structures, French Challenges, Dutch Models, and the Early Modern Swiss Confederation», en HOLENSTEIN, A., MAISSEN, T. y PRAK, M. (eds.): The Republican Alternative. The Netherlands and Switzerland compared. Amsterdam, Amsterdam University Press, 2008, pp. 125-150.

MARÉCHAUX, B.: Instituciones navales y finanzas internacionales en el Mediterráneo de la época moderna. Los asentistas de galeras genoveses al servicio de la Monarquía Hispánica (1500-1650). Tesis doctoral inédita, Universidad Carlos III, Madrid, 2017.

MORIEUX, R.: «Diplomacy from Below and Belonging: Fishermen and Cross-Channel Relations in the Eighteenth Century», Past E Present, 202, 1, 2009, pp. 83-125.

ONNEKINK, D. (ed.): War and Religion after Westfalia, 1648-1713. Farnham, Asghate, 2009.

PACINI A.: I presuppostipolitici del «Secolo dei Genovesi»: la riforma del 1528. Génova, Società Ligure di Storia Patria, 1990.

PETTI BALBI, G.: «Le nazione italiane all'estero», en FRANCESCHI, F., GOLDTHWAITE, R. A. y MUELLER, R. C. (eds.): Il Rinascimento italiano e l'Europa, Vol. IV, Commercio e cultura mercantile. Treviso-Costabissara, Fondazione Cassamarca-Angelo Colla Editore, 2007, pp. 397-423.

RIBOT GARCÍA, L. A.: "Ira regis o clementia. El caso de Mesina y la respuesta a la rebelión en la Monarquía de España», en Visperas de sucesión. Europa y la Monarquía de Carlos II, ÁlVAREZ-OSSORIO, A. y GARCÍA, B. (eds.). Madrid, Fundación Carlos de Amberes-Edición Doce Calles, 2015, pp. 129-157.

RIVERO RODRÍGUEZ, M.: El conde duque de Olivares. La búsqueda de la privanza perfecta. La Corte en Europa, vol. 20, Madrid, Polifemo, 2017.

RIVERO RODRÍGUEZ, M.: «Como un cordero entre lobos: La recuperación de la iniciativa política y diplomática española en Italia (1648-1664)», en SANZ CAMAÑES, P.

Ediciones Universidad de Salamanca / అ@@ Stud. his., H. ${ }^{a}$ mod., 41, n. 1 (2019), pp. 189-230 
(ed.): Tiempo de cambios. Guerra, diplomacia y politica internacional de la Monarquía Hispánica (1648-1700). Madrid, Editorial Actas, 2012, pp. 365-385.

RUIZ IBÁÑEZ, J. J. y PÉREZ TOSTADO, I. (coords.): Los exiliados del rey de España. Madrid, Fondo de Cultura Económica, 2015.

SANZ AYÁN, C.: Un banquero en el Siglo de Oro. Octavio Centurión, el financiero de los Austrias. Madrid, La Esfera de los Libros, 2015.

SANZ AYÁN, C.: Los banqueros y la crisis de la Monarquía Hispánica de 1640. Madrid, Marcial Pons, 2013.

SCHAUB, J.-F.: La France espagnole. Les racines hispaniques de l'absolutisme français. París, Le Seuil, 2003.

SCHAUB, J.-F.: «La Peninsola Iberica nei secoli XVI e XVII: la questione dello stato», Studi Storici 36, 1995, pp. 9-50.

SCHILLINGER, J.: «La Franche-Comté et les enjeux diplomatiques du Cercle de Bourgogne à la Diète de Ratisbonne 1667-1674», Revue d'Histoire Moderne et Contemporaine, XXXIX, 1992, pp. 531-550.

SÉRÉ, D.: La paix des Pyrénées. Vingt-quatre ans de négociations entre la France et l'Espagne (1635-1659). París, Honoré Champion, 2007.

SUBRAHMAYAM, S.: «On the significance of Gadflies: the Genoese East India Company of the 1640s", Journal of European Economic History, 17, 3, 1988, pp. 559-581.

VAN GELDEREN, M. y SKINNER, Q., (eds.): Republicanism: a Shared European Heritage. 2 vols., Cambridge, Cambridge University Press, 2002.

VENEROSO, G. B.: Genio ligure risvegliato. Génova, 1650.

TILLY, C. y BLOCKMANS, W. P. (eds.): Cities and the Rise of States in Europe, A.D. 1000 to 1800. San Francisco y Oxford, Westview Press, 1994.

VITALE, V.: La diplomazia genovese. Milan, Istituto per lo studio di política internazionale, 1941.

WATKINS, J., «Towards a New Diplomatic History of Medieval and Early Modern Europe», Journal of Medieval and Early Modern Studies, 38, 2008, pp. 1-14.

WELLER, T.: «Las repúblicas europeas y la Paz de Westfalia: la representación republicana en las negociaciones de Münster y Osnabrück», en HERRERO SÁNCHEZ, M. (ed.): Republicas y republicanismo en la Europa Moderna (siglos XVI-XVIII). Madrid, Fondo de Cultura Económica, 2017, pp. 329-347.

WELLER, T.: «Merchants and Courtiers. Hanseatic Representatives at the Spanish Court in the Seventeenth Century», Dimensioni e problemi della ricerca storica, 1, 2014, pp. 73-98. 